\title{
El desarrollo de una política pública: el reconocimiento dela objeción de conciencia y la prestación social sustitutoria
}

JoséVicente Lorenzo Jiménez*

\section{Introducción}

El presente estudio tiene por objeto analizar la aparición, desarrollo y terminación de una política pública muy concreta, la relativa al reconocimiento de la condición de objetor de conciencia al servicio militar y a la gestión de la prestación social sustitutoria, desarrollada entre los años 1978 y 2001.

Se ha puesto especial atención en cuatro clases de fuentes. En primer lugar, el libro editado por el propio M inisterio de Justicia, La O bjeción de Conciencia y la Prestación Social Sustitutoria en España, muy útil por la gran cantidad de información que recogel. En se gundo lugar, la prensa periódica de la época, con noticias muy abundantes sobre la materia. En tercer lugar, los Informes anuales del D efensor del Pueblo, en los que se recogen las diversas quejas re cibidas. Y en cuarto lugar, los Diarios de Sesiones del Congreso de los D iputados y del Senado, que recogen las comparecencias de los altos cargos competentes en la materia ante las correspondientes comisiones parlamentarias, y que son muy significativas, pues los comentarios y preguntas de los parlamentarios reflejan el sentir político y social sobre la materia; y los de los altos cargos a su vez reflejan las actuaciones y resultados de la política pública?.

El estudio permite comprobar las enormes dificultades para implantar una política pública, previamente decidida y reflejada en los correspondientes textos normativos, cuando se produce una oposición, activa o pasiva, por parte de los diversos actores y destinatarios, lo que exige una gran voluntad política, que muchas veces no existe o se vacía ante tal oposición.

\section{Los comienzos de la política pública}

\section{Los antecedentes en la época preconstitucional}

Durante muchos años la cuestión de los objetores que se negaban a realizar el servicio militar fue cuantitativamente insignificante, en cuanto afectaba a muy pocas personas, principalmente Testigos de Jehová, pero cualitativamente muy importante, ya que planteó graves problemas políticos, hasta el punto de que las Cortes franquistas llegaron a rechazar los proyectos del Gobierno dirigidos a conseguir la despenalización de estas conductas. H ubo que esperar a 1976 para alcanzar una solución provisional: el Real D ecreto 3011/1976, de 23 de diciembre (luego desarrollado por Circular del M inisterio de D efensa de 8 de noviembre de 1977), fue la primera norma que reconoció una objeción al servicio militar no constitutiva de delito. Esta norma, que regulaba las prórrogas de incorporación a filas por motivos de objeción de carácter religioso, enfocaba la cuestión como una prórroga por razones de interés nacional.

\section{Las previsiones de la Constitución de 1978}

Los constituyentes de 1978 optaron por contemplar expresamente el problema de la objeción de conciencia y buscaron una 
solución de compromiso: la Constitución recogió sin discusión alguna la existencia del servicio militar obligatorio, pero introdujo la previsión de la objeción de conciencia, a la que calificaba como causa de exención de aquél, remitiéndose a una futura de cisión legislativa para regular esta materia, añadiendo que se podía establecer una prestación social sustitutoria.

\section{La falta de desarrollo de la política pública durante muchos años. El revulsivo del Tribunal Constitucional}

Durante varios años, los poderes públicos no adoptaron ninguna decisión, aunque se elaboraron varios proyectos. $Y$, sin embargo, los problemas seguían planteándose. $H$ asta que varios de tales problemas Ilegaron al Tribunal Constitucional. Éste declaró que la objeción de conciencia era un derecho reconocido por la Constitución, por lo que no necesitaba de un desarrollo legislativo para su aplicación inmediata, concretándose su contenido esencial en el aplazamiento de la incorporación a filas: por tanto, mientras no se regulase el procedimiento para el reconocimiento de la condición de objetor, éste estaba exento del deber de incorporarse a filas, quedando en situación de «ncorporación aplazada» (Sentencia 15/82, de 23 de abril). Ello obligaba al legislador a incluir el problema en su agenda, pues de lo contrario los afectados se beneficiarían de una exención del servicio militar sin contrapartida de una prestación sustitutoria.

\section{La regulación por normas con rango de ley en 1984}

Sobre esta base se legisló en 1984 acerca de la objeción de conciencia al servicio militar. La regulación se desglosó, por motivos formales, en dos normas con rango de ley, aprobadas ambas el 26 de diciembre de 1984: la Ley O rgánica 8/1984, que re gulaba cuestiones jurisdiccionales y penales; y la Ley 48/1984, que regulaba la objeción de conciencia y la prestación social sustitutoria.

La regulación establecía que los objetores debían declararse tales. Para asegurar la seriedad de esa declaración se contemplaba un órgano colegiado (el Consejo $\mathrm{N}$ acional de $\mathrm{O}$ bjeción de Conciencia) encargado de examinarla y de reconocer la condición de objetor. Éstos estaban obligadosa realizar una prestación, consistente en una actividad de utilidad pública en al guno de los sectores legalmente previstos, en entidades dependientes de las Administraciones 0 en entidades sin fin de lucro que sirvieran el interés general de la sociedad.

La Exposición de M otivos de la Ley, tras indicar que la objeción de conciencia constituía una derivación del derecho a la libertad ideológica, religiosa y de culto, añadía que los principios en los que se basaba la regulación eran los siguientes:
- M áxima amplitud en cuanto a las causas de la objeción, con la mínima formalidad posible en el procedimiento y la mayor garantía de imparcialidad en cuanto a la declaración.

- Eliminación de toda discriminación entre quienes cumplieran el servicio militar y los objetores de conciencia.

- Previsión de garantías suficientes para asegurar que la objeción de conciencia no sería utilizada, en fraude de la Constitución, como una vía de evasión del cumplimiento de los deberes constitucionales. De hecho, se concretaba en una duración de la prestación social superior a la del servicio militar, que debería fijarse por Real D ecreto. Además, el Consejo podía denegar la solicitud cuando, sobre la base de los datos e informes de que dispusiera, percibiera incongruencia entre los motivos y manifestaciones alegados por los solicitantes y las conclusiones que se desprendieran de las actuaciones obrantes en el expediente.

- Consecución de que el cumplimiento de la prestación re dundara en beneficio de la sociedad y del propio objetor.

La regulación se completaba con un régimen sancionador; así como con la tipificación de una serie de delitos (la ausencia arbitraria, la falta de incorporación y la negativa a cumplir la prestación) castigados con penas privativas de libertad.

\section{El rechazo de la Ley por los destinatarios de la misma}

La regulación de 1984 provocó importantes rechazos de tipo jurídico, político, ideológico y social. En concreto, el D efensor del Pueblo interpuso un recurso de inconstitucionalidad y la Audiencia Nacional planteó varias cuestiones ante el Tribunal Constitucional, lo que suponía una deslegitimación implícita de la regulación, en cuanto se ponía en duda la constitucionalidad de ésta.

También los movimientos de objetores de conciencia se opusieron a la nueva regulación y a su aplicación, que, en consecuencia, no logró integrar a sus presuntos destinatarios, de forma que trataba de resolver unos problemas cuyos afectados no aceptaban sus soluciones. Es muy significativo que, de los 15.208 objetores reconocidos a 31 de diciembre de 1986, 5.322 de ellos rehusaran la prestación como Testigos de Jehová; 5.474 rehusaran la prestación en un escrito colectivo del M ovimiento de 0 bjeción de Conciencia; 304 solicitaran la exención de la prestación; y sólo 4.108 (es decir, un 27\%) se abstuvieran de realizar especiales manifestaciones (M J, 165). Sorprendentemente, como veremos, la Ley fue pronto acogida por otros sectores en los que no se había pensado. 


\section{El atraso en la puesta en práctica de la política pública}

La Ley exigía un desarrollo tanto reglamentario como organizativo, lo que se produjo de manera muy parcial en los primeros momentos, como consecuencia de la situación de incertidumbre derivada de los recursos y cuestiones de inconstitucionalidad planteados, y que no fueron resueltos por el Tribunal Constitucional hasta 27 de octubre de 1987. Se mantuvo así empantanado un problema que seguía siendo cualitativamente importante, pero de una importancia cuantitativa aún muy escasa, aunque creciente.

En un primer momento, como decimos, sólo se desarrolló un aspecto muy concreto, la organización del Consejo Nacional de 0 bjeción de Conciencia y el reconocimiento de la condición de objetor, por Real Decreto 551/1985, de 24 de abril, Reglamento promovido por los M inisterios de Presidencia y Justicia. Es decir, se desarrolló únicamente una de las dos patas en las que se basaba el sistema, el reconocimiento de la condición de objetor, mientras que dejó sin desarrollarse la regulación de la prestación social. Ello supuso el comienzo de la producción de la bolsa de objetores reconocidos, pero que sin embargo no podían realizar ningún tipo de prestación, al no haberse estructurado ésta.

\section{La constitución y funcionamiento del Consejo Nacional de 0 bjeción de Conciencia para el reconocimiento dela condición de objetor}

La dependencia y composición del Consejo Nacional de 0 bjeción de Conciencia, constituido el 13 de junio de 1985, reveló desde el primer momento sus disfuncionalidades. Según la Ley, se integraba en el M inisterio de la Presidencia, es decir, en un M inisterio que constituía un cajón de sastre. Pero por Real D ecreto 1519/1986, de 25 de julio, las funciones asignadas al M inisterio de la Presidencia en materia de objeción se atribuyeron al M inisterio de Justicia, adscribiendo a éste los órganos correspondientes.

Por lo que se refiere a la composición del Consejo, la intervención del M inisterio de Defensa era muy minoritaria. Sólo uno de sus cinco miembros era designado por ese Ministerio. Por el contrario, el M inisterio de Justicia nombraba dos.

Por lo que se refiere a las funciones del Consejo, la Ley era muy oscura en su regulación, fuera del aspecto del reconocimiento de la condición de objetor, ya que no existía una clara delimitación de competencias con el órgano de gestión einspección del régimen de la prestación social previsto en la Ley. En un primer momento parecía pensarse que el Consejo iba a ser el órgano encargado de asignar las plazas y de desarrollar gran parte de las funciones que luego se asignarían a la 0 ficina para la Pres- tación Social de los 0 bjetores de Conciencia 0 , al menos, la función de dirigir a ésta?.

Por lo que se refiere a la dinámica real de los hechos, el Consejo reveló muy pronto su absoluta inutilidad. Teóricamente su función era la de examinar las solicitudes de reconocimiento de la condición de objeción y rechazar las que no fueran serias. Pero su actividad de comprobación fue nula, como lo demuestra el hecho de que la proporción entre los declarados y reconocidos era muy alta; debiéndose la mayor parte de las denegaciones de reconocimiento a motivos formales y a supuestos de imposibilidad del reconocimiento (mujeres, menores de edad, etc.). La «exposición detallada de los motivos de conciencia» en la práctica quedó reducida a una mera invocación de «motivos religiosos, éticos, morales, humanitarios y filosóficos", sin mayores especificaciones. Lo cual acredita que la función de este órgano era me ramente nominal y que realmente para tal función no era necesario un órgano como el contemplado por la Ley4.

\section{La O ficina para la Pestación Social de los 0 bjetores de Conciencia como órgano de gestión de la prestación}

La Ley contemplaba la creación de un órgano en el Ministerio de la Presidencia para la gestión einspección de la prestación, y justificaba su integración en este M inisterio por el carácter coordinador del mismo, así como con el argumento de que en la materia estaban implicados varios M inisterios. Pero de hecho el encuadre orgánico era muy discutible, ya que en este punto realmente no se ejercían funciones de coordinación, y si al gún tipo de coordinación era requerido, realmente lo era con las Comunidades Autónomas y corporaciones locales, que eran, como luego veremos, las competentes en los sectores en que podía realizarse la prestación.

En cumplimiento de lo previsto en la Ley, se creó en el M inisterio de la Presidencia una 0 ficina para la Prestación Social de los 0 bjetores de Conciencia, que pasó después a depender de la Subsecretaría de Justicia (Real D ecreto 1519/1986, de 25 de julio).

Esta 0 ficina tenía encomendada la creación de plazas mediante la firma de conciertos con determinadas entidades, para que los objetores pudieran realizar la prestación en ellas. Por lo que se refiere a los objetores, las funciones de la 0 ficina comenzaban tras el reconocimiento de la condición de tal por el Consejo, y consistían en determinar su situación mediante la concesión, en su caso, de exenciones o aplazamientos; ordenar la incorporación de los mismos a la prestación social; y efectuar el seguimiento e inspección de la prestación.

Cabe observar, pues, que las funciones eran de mero encuadramiento y de seguimiento de la prestación, puesto que la Ley 
preveía que la prestación social se realizaría en las entidades con las que se firmaran los correspondientes conciertos.

\section{La aprobación del Reglamento de la Prestación Social y sus vicisitudes judiciales}

No obstante, la 0 ficina no podía comenzar sus tareas de búsqueda de plazas y de gestión directa con los objetores hasta que no existiera un Reglamento de la Prestación Social. La aprobación de este Reglamento, sin embargo, se demoró hasta que el Tribunal Constitucional resolvió los recursos que ponían en duda la constitucionalidad de la Ley. Eliminada esta fuente de incertidumbre, el Reglamento se aprobó por Real D ecreto 20/1988, de 15 de enero de 1988.

Sin embargo, ese Reglamento fue recurrido ante el Tribunal Supremo, abriéndose otra vez la situación de incertidumbre, que se agravó cuando este Tribunal dictó Sentencia de 12 de enero de 1990 declarándolo contrario a D erecho, por haberse dictado sin previo trámite de audiencia a los interesados. En estas circunstancias, la Administración se vio obligada a interponer re curso de revisión ante el propio Tribunal Supremo, que, si bien suspendió la ejecución de la Sentencia y al final estimó el recurso por Sentencia de 21 de noviembre de 1990, prolongó la situación de incertidumbre. Por fin, por Sentencia de 18 de junio de 1991 se declaró la validez del Reglamento (M J, 219).

El resultado de todo ello fue una victoria pírrica para el M inisterio de usticia. Por un lado, supuso una nueva pérdida de legitimidad del sistema, ya que hacía suponer la existencia de múltiples defectos en las normas reguladoras de la materia, y demostraba la oposición de numerosos actores, entre ellos, los órganos judiciales. Por otro lado, supuso un notable retraso en el desarrollo de esa política pública, pues durante el periodo en cuestión la actividad administrativa estuvo prácticamente paralizada, ante la eventualidad de que el Reglamento fuera declarado definitivamente inválido, con el consiguiente problema de los efectos de los actos realizados en su aplicación. Sólo después de dictarse la Sentencia de 18 de junio de 1991 pudo actuarse con un mínimo de seguridad.

\section{La «amnistía» de los objetores anteriores a 1988}

Nótese que el Reglamento de la prestación social sustitutoria se aprobó nada menos que a los 9 años de la Constitución; y su definitiva validez se produce a los casi 13. Entre tanto, muchos jóvenes se habían ido declarando objetores y el Consejo los había reconocido como tales. Y, sin embargo, la falta del Reglamento de la Prestación Social había impedido la realización del servicio sustitutorio.
Ello planteaba una serie de problemas. Por un lado, se había creado una bolsa de objetores - que entonces parecía importante- a la que no se podía dar salida por no haberse creado aún las correspondientes plazas para realizar la prestación.

Además, por el transcurso de un tiempo tan largo, muchos de los objetores habían al canzado edades relativamente el evadas, y habían ido consolidando unas situaciones personales (matrimonio, hijos, trabajo) difícilmente compatibles con una prestación social forzosa mínimamente rigurosa. Era evidente que su llamamiento para hacer tal prestación iba a dar origen a numerosos y difíciles problemas personales y familiares. $\mathrm{H}$ ay que recordar que por entonces la edad no constituía una causa de exención, sino sólo de reducción del servicio militar, al menos hasta llegar a la edad de licencia absoluta a los 34 años.

De ahí que se adoptara una decisión complementaria por Real D ecreto 1442/1989 de 1 de diciembre: una exoneración de sus obligaciones, mediante su pase directo a la reserva, a todos los que se hubieran declarado objetores antes de 10 de febrero de 1988.

Es muy significativa la terminología utilizada para referirse a esta exoneración de la prestación: se habló entonces de una samnistía», como si el cumplimiento de tal prestación constituyera una sanción penal, y no una mera obligación sustitutoria del servicio militar, con lo que suponía de desegitimación de la institución.

La medida supuso un alivio tanto para las personas afectadas como para el propio M inisterio de Justicia, que se deshacía de una bolsa importante de objetores para la que no existían plazas de prestación. Pero socialmente empezó a cundir la idea de que el declararse objetor podía constituir una vía para evitar el cumplimiento tanto de las obligaciones militares como de las posibles obligaciones subsidiarias. D esde este punto de vista, los aspirantes a objetor podían contemplar la realización de la prestación como un juego de azar: ciertamente existía la posibilidad de que el interesado fuera llamado para cumplirla al cabo de varios años, con el consiguiente perjuicio, pero el riesgo de que ocurriera parecía en aquella época muy reducid 05.

\section{El desarrollo de la política pública entre 1989 y 1993}

\section{La estructura organizativa}

Una vez aprobado el Reglamento de la Prestación Social, con los matices ya indicados, se abría el camino para el pleno desarrollo de esta política pública. En aquel momento, como he- 
mos dicho, existía ya una estructura administrativa, en concreto el Consejo y la $O$ ficina, siendo esta última la encargada de gestionar la prestación social. Ambos órganos tenían un funcionamiento independiente, sin que existiera más coordinación que la derivada de su común integración en la Subsecretaría de Justicia.

A ello hay que añadir que durante mucho tiempo la organización fue bastante precaria, lo que quedó reflejado en los propios presupuestos de gastos. En concreto, se pasó de un presupuesto de 568 millones de pesetas en 1986 a otro de sólo 74 millones en 1988. En 1989 se elevó a 1.125 millones, pero luego fue reduciéndose, hasta pasar a 843 millones en 1992. Pero ade más los presupuestos no sólo eran reducidos, sino que ni siquiera se ejecutaban. Así, en 1988 el presupuesto sólo se ejecutó en un $12 \%$, mientras que los presupuestos de 1989, 1990 y 1991 se ejecutaron, respectivamente, en el $54 \%, 52 \%$ y $76 \%$ (M), 172173 y 175).

\section{El incesante aumento del número de objetores}

La organización estuvo siempre desbordada por las necesidades. En este periodo (1989-1993), en efecto, se produjo un salto sustancial en las declaraciones de objeción, que pasaron de 13.130 en 1989 a 68.209 en 1993 (M J, 147). Este dato iba a ser determinante de toda la política seguida en la materia, ya que los órganos competentes tenían que hacer frente a esta aval ancha y tratar de cumplir las previsiones legales.

Ante esta situación, habría que preguntarse por las causas de la amplitud de la objeción de conciencia y por el perfil de quienes se declaraban tales.

Como ya hemos indicado, el colectivo al que real mente iba dirigida la regulación no la aceptó. La mayor parte de los verdaderos objetores de conciencia real mente no se integraron en el sistema, sino que pasaron a la insumisión pura y simple, con las consecuencias penales procedentes. La oposición al sistema se encarnó en los movimientos de objeción de conciencia y antimilitaristas.

Sin embargo, inmediatamente comenzaron a declararse objetores muchos jóvenes con el propósito confesado de evitar el servicio militar. En este periodo, el perfil del objetor tenía unas caracte rísticas bastante homogéneas. La objeción de conciencia era todavía un fenómeno minoritario (en relación con todo el colectivo de jóvenes en principio llamado a cumplir sus obligaciones militares), siendo el objetor una persona de cierta edad, residente en un medio urbano y con estudios superiores o medios. Es muy significativo el dato de que quienes se declaraban objetores no lo hacían en la fecha del reemplazo, sino desde una situación de aplazamiento por estudios. Es también muy significativo que el porcentaje de objetores que trabajaba era superior a la media de jóvenes de su edad, y su empleo más cualificado (MJ, 166-167).
Todo ello revela que el motivo real de muchos de los que se declaraban objetores no era el de ser contrarios al uso de las armas, sino el de evitar el cumplimiento de unas obligaciones militares incompatibles con el trabajo o los estudios o con la vida que se venía llevando, con la creencia de que ello tampoco conllevaría la realización de una prestación social. El propio sistema contribuía a que los objetores aspiraran incluso a eximirse de la propia prestación, bien por la falta de plazas para realizarla (lo que haría imposible su llamamiento); bien por la esperanza de nuevas «amnistías» como la del año 1989; bien por tratar de conseguir una exención 0 , al menos, una reducción del periodo.

En efecto, en los primeros tiempos, en que la demora en el llamamiento era tanta, se aprovechó por muchos para dilatar hasta el final las prórrogas del servicio militar y declararse entonces objetor, de modo que, mientras se les reconocía tal condición y se les llamaba, podían alcanzar los 28 años, edad que suponía la reducción de la prestación a nueve meses (la mitad de la ordinaria); o incluso la exención por sostenimiento familiar. Posteriormente, con la entrada en vigor de la Ley del Servicio Militar de 1991, que suprimió la reducción por edad, sustituyéndola por una exención a partir de los 30 años, numerosos objetores quedaron exentos por al canzar esta edad sin haber sido llamados6. Empezó a hablarse entonces del «objetor de conveniencia», caracterizado por su intención de evitar la realización del servicio militar, sin que su actitud fuese realmente antimilitarista o pacifista.

Por otro lado, determinadas circunstancias indudablemente incidieron en el espectacular aumento de objetores. Entre ellas cabe destacar, muy especialmente, la psicosis que se desató con motivo de la guerra del $\mathrm{G}$ olfo y el envío de fragatas españolas con marineros de reemplazo en los años 1990 y 1991. Efectos parecidos se produjeron ante la aparición de determinadas noticias luctuosas en el ámbito militar (muertes por accidentes, maltratos y novatadas en los cuarteles, abusos de autoridad, etc.).

Para asegurar la seriedad de la declaración de objetor, se estableció una duración de la prestación social superior a la del servicio militar, que se créa disuasoria7. El Reglamento de la Prestación Social de 1988 fijó la duración de ésta en 18 meses (la del servicio militar era de 13). Posteriormente la duración de la prestación se fijó en 13 meses (Real Decreto 525/1992 de 22 de mayo), como consecuencia de la reducción del servicio militar a 9 meses. Sin embargo, esta mayor duración no supuso un freno excesivo a la avalancha de declaraciones de objeción.

¿Cómo reaccionó el M inisterio de Justicia ante esta situación? Teóricamente podía seguir varias políticas: dado que su tarea fundamental era conseguir que los objetores pudieran realizar la prestación, podía optar bien por la reducción de la oferta de objetores, bien por el aumento de plazas de prestación que asumiera dicha oferta. Veamos qué fue lo que hizo. 


\section{La labor de reconocimiento por parte del Consejo Nacional de Objeción de Conciencia}

La función del Consejo era la de garantizar la seriedad de las declaraciones de objeción. Sin embargo, ante la avalancha de éstas, el Consejo siguió actuando como lo había hecho hasta entonces, aduciendo que no podía entrar a valorar los motivos de objeción, entendiendo esto de una manera absoluta, ya que prácticamente sólo por motivos formales o por carencia absoluta de fundamento se denegaba el reconocimiento de la objeción8.

Se daban así casos sorprendentes de reconocimientos como objetores de conciencia a personas que habían cometido hechos violentos; a policías municipales - que forman parte de un Cuerpo funcionarial que, por definición legal, es armado- ; a personas que luego habían tratado ingresar como personal profesional de tropa y marinería; a personas que trabajaban en establecimientos militares, etc. 9 .

De esta forma, los reconocimientos de la condición de objetor pasaron en este periodo de 12.140 a 46.084.

En estas circunstancias, toda la actuación del Ministerio de Justicia y, en particular, del Consejo $N$ acional de $O$ bjeción de Conciencia, partió de una hipótesis que inmediatamente se de mostró falsa: considerar que la declaración de objeción era una opción de minorías. Al renunciar a adoptar toda medida de control, la opción era elegida por cada vez más personas, con lo que el modelo de servicio militar obligatorio y de un servicio subsidiario - y, en consecuencia, minoritario- se convertía a la larga en inviable.

\section{La política de creación de plazas para la realización de la prestación social}

Partiendo de la base de la existencia de objetores reconocidos como tales que debían realizar su prestación, la primera cuestión que se planteaba era la de determinar los sectores en los que se podría desarrollar ésta.

La propia Ley, luego concretada por el Acuerdo del Consejo de M inistros de 11 de marzo de 1988, indicaba los posibles sectores: protección civil; conservación del medio ambiente, mejora del medio rural y protección de la naturaleza; servicios sociales; servicios sanitarios; programas de cooperación internacional; y educación y cultura.

No obstante, no parece que se tuviera mucha fe en la eficacia de la prestación social, al menos en el plano legislativo. Sólo dos Leyes estatales sectoriales aludían a la prestación. Una era la Ley 13/1982, de 7 de abril, de Integración Social de los M inusválidos, dictada cuando aún no estaba regulada la prestación social, siendo muy genérica la mención que se hace a ésta en su art. 64.3. La otra Ley era la 2/1985, de 21 de enero, de Protección Civil, que se limitaba a establecer una obligación especial de colaboración de los objetores. En el ámbito autonómico sólo en el sector de los servicios sociales se dictaron leyes autonómicas que aludían tangencialmente a la prestación, sin ningún detalle, y confundiendo en muchas ocasiones la institución de la prestación social con la del voluntariado10.

D esde otra perspectiva, salta inmediatamente a la vista que, salvo la cooperación internacional, los sectores en los que se podía realizar la prestación no eran de la competencia del Estado, sino de las Comunidades Autónomas (salvo en aquellas en que las competencias de salud y educación aún no estaban transferidas) y de los entes locales (Ayuntamientos y D iputaciones).

Esta circunstancia ya de por sí excluía la posibilidad de que los objetores dependieran jerárquicamente de un órgano del Estado encargado de gestionar los servicios en los que intervendrían aquéllos, al modo de lo que ocurría en el servicio militar, en el que los militares de reemplazo formaban parte de una estructura jerarquizada integrada en el M inisterio de D efensa. Además, en los sectores en que debía realizarse la prestación ya existían organismos y entidades encargados de la gestión de tales competencias.

Por otra parte, la Ley establecía expresamente que la realización de la prestación no debía suponer dependencia orgánica de instituciones militares.

Por ello, las funciones de la 0 ficina contempladas en la Ley se reducían a facilitar objetores a las entidades con competencias 0 que realizaban actividades en los sectores previstos y, en su caso, a inspeccionar el cumplimiento de la prestación.

Asimismo, la Ley optó por un sistema de voluntariedad de las entidades en lo referente a la recepción de objetores, lo que jurídicamente se concretaba en la necesidad de firmar los correspondientes conciertos. Es decir, el Estado renunciaba a imponer obligatoriamente objetores a las entidades, siendo éstas las que, en caso de estar interesadas, debían solicitarlos al M inisterio de Justicia. La Ley otorgaba preferencia a las Administraciones Públicas a la hora de realizar la prestación, pero también podía realizarse en entidades privadas. No obstante, con el fin de evitar un excesivo «minifundismo», se decidió que los conciertos debían contemplar un número mínimo de tres puestos para objetores.

En consecuencia, una de las primeras tareas de la 0 ficina fue la de buscar plazas, para lo cual era necesario contar con el consentimiento de las entidades, mediante la correspondiente negociación. A estos efectos, el M inisterio de Justicia manejaba una serie de argumentos. El más evidente era el de la utilidad que para la propia entidad supondría la realización de tareas de utilidad pública por parte de los objetores. Pero hubo otro argumento de peso, especialmente utilizado respecto a los entes munici- 
pales y autonómicos: el beneficio de los propios objetores, para facilitarles la posibilidad de realizar la prestación y evitar los perjuicios que las demoras estaban causando a aquéllos, muchos de los cuales llevaban varios años de espera.

En un primer momento el Ministerio de Justicia optó por concertar predominantemente con entidades públicas (Ayuntamientos, Diputaciones y Comunidades Autónomas); y entre las privadas, con aquellas que contaban con una organización extensa (principalmente, Cruz Roja). Pronto, sin embargo, cuando la necesidad de plazas se hizo más perentoria, los conciertos se diversificaron11. De esta forma, entre 1988 y 1993 las entidades con concierto pasaron de 44 a 1.729. En 1993 los puestos concertados eran 35.614 (M), 213).

Sin embargo, tal política se encontró con diversos problemas. En primer lugar, el hecho de que la asunción de objetores fuera un acto voluntario de las entidades significaba que había que contar con el consentimiento de éstas. Sin embargo, en de terminados lugares se produjeron actitudes de boicot a la prestación (por ejemplo, en la Comunidad Autónoma y Ayuntamientos vascos; en Ayuntamientos gobernados por grupos políticos opuestos a la prestación social).

Por otra parte, a pesar del gran esfuerzo en la creación de plazas concertadas, éstas crecían a un ritmo muy inferior al del cre cimiento del número de objetores, lo que conducía el sistema al fracaso.

\section{Las dificultades en la realización de la prestación social}

En virtud del concierto firmado entre el M inisterio de Justicia y cada entidad, aquél se comprometía a asignar objetores has ta un máximo de las plazas concertadas. Es decir, el M inisterio de Justicia no se comprometía a asignar el número de objetores indicado en el concierto, sino hasta ese número. A su vez, las entidades se comprometían a dar ocupación efectiva durante 35 horas semanales a los objetores que se les asignasen (M J, 193), sin que éstos pudieran ser utilizados en puestos de plantilla 0 en sustitución de empleados.

Sin embargo, esto fue también una fuente de dificultades. Por lo que se refiere a la asignación de objetores a las entidades, se produjeron graves desequilibrios territoriales entre la demanda y la oferta de aquéllos. En efecto, ocurría que en determinadas zonas geográficas se habían creado plazas y eran necesarios objetores, pero sin embargo no los había en tales lugares. Era lo que pasaba, en un primer momento - precisamente por ser la objeción un fenómeno urbano- , en las zonas rurales, en las que existían plazas concertadas con las Asambleas L ocales de C ruz Roja; y con actividades de medio ambiente y conservación de la natural eza, para las que se crearon plazas concertadas con las
Confederaciones H idrográficas. Frente a ello, por el contrario, el M inisterio era incapaz de colocar, por falta de plazas, a muchos objetores, especialmente en las grandes ciudades.

Para conseguir un equilibrio territorial entre la demanda y oferta de objetores, hubiera sido precisa una enérgica política de creación y cobertura de plazas con alojamiento y manutención. $Y$, sin embargo, no se hizo, posiblemente por su al to coste presupuestario y por la falta de infraestructura suficiente de las entidades que ofertaban plazas en esos lugares, pero también - y probablemente fue la razón principal - por su alto coste político (M), 181-182). Lo cual a su vez dio lugar a un efecto perverso: en los lugares en que existían plazas pero no objetores, las propias entidades hicieron proselitismo para que personas que en un principio estaban dispuestas a hacer el servicio militar, se de clararan objetores para poder cubrir los puestos en cuestión. Se comenzó así a producir el efecto de la pescadilla que se muerde la cola: la política de creación de plazas para la prestación social generaba a su vez un importante aumento del número de obje tores, para cuya colocación era necesario a su vez crear nuevas plazas.

El resultado fue que, a pesar de haberse creado numerosos puestos para que los objetores realizaran la prestación, las cifras de los que la hacían eran muy poco significativas. Así, a 31 de marzo de 1991 sólo habían terminado su prestación 148 objetores. A 19 de junio de 1991 sólo 2.151 objetores se encontraban en situación de actividad, a pesar de existir más de 13.000 puestos teóricos'12.

A ello cabe añadir que el llamamiento era muy burocrático. El M inisterio de Justicia hacía el llamamiento o selección de los que debían incorporarse (una o dos veces al año), se notificaba a los interesados, a los que se daba un plazo para elegir destino («manifestación de preferencia»), y se les asignaba y ordenaba la incorporación, que tendría lugar en los meses siguientes. La situación se complicaba aún más cuando el interesado recurría los diversos actos del Ilamamiento, lo que era relativamente frecuente13. De esta forma, muchas entidades tenían los puestos sin cubrir, a sabiendas de que simultáneamente había numerosos obje tores, incluso en la misma localidad, a la espera de ser llamados o de incorporarse.

\section{La actuación de los Ministerios de Justicia de D efensa ante esta situación}

Durante los primeros tiempos de este periodo no hay una conciencia en los órganos superiores de la Administración del Estado acerca de la gravedad del problema.

En el Ministerio de Justicia la agenda política establecía una serie de temas mucho más prioritarios (la eterna reforma de la 
administración de justicia, la reforma de los establecimientos penitenciarios, la labor legislativa), de tal manera que el desarrollo de la política pública que tratamos se dejó a los escal ones más inferiores del M inisterio14. D e hecho, tanto la 0 ficina como la Secretaría del Consejo tenían rango de Subdirecciones $G$ enerales, a cuyo frente no se encontraba un político, sino un funcionario, 10 que disminuía su poder de decisión. Además, ambos órganos estaban encuadrados en la Subsecretaría del M inisterio, auténtico cajón de sastre, lo que dificultaba las posibles iniciativas de actuación. H ubo que esperar a 1992 para que ambos órganos se integraran en una misma Dirección General, al entrar a formar parte de la D irección General de Asuntos Religiosos y de 0 bjeción de Conciencia (Real D ecreto 266/1992, de 20 de marzo).

A ello había que añadir que el M inisterio de Justicia no contaba con una tradición o cultura de gestión de amplios colectivos de personas, como era el caso de la política pública que estamos analizando15.

Por el contrario, la existencia de una cultura propia del M inisterio de Justicia dio lugar a que su actuación estuviera imbuida en la idea de la protección de los derechos del objetor, tanto en el momento desu reconocimiento como en el momento de la realización de su prestación. Ello supuso, por un lado, olvidar que la objeción constituía una mera exención del servicio militar, no un derecho absoluto, colocando en un segundo plano los intereses del M inisterio de D efensa. Y, por otro lado, en los conflictos que surgían entre las entidades y los objetores en el momento de la prestación, la tendencia era hacer prevalecer los intereses de éstos. Así, por ejemplo, eran muy numerosas las declaraciones de los políticos manifestando que una de las labores fundamentales del $M$ inisterio era la de evitar que los objetores ocuparan puestos de trabajo; en cambio, eran muy pocas las declaraciones relativas a la necesidad del cumplimiento riguroso de la prestación y de conseguir con ésta la mayor rentabilidad social.

Por lo demás, la labor del M inisterio durante este período estuvo centrada en el reconocimiento de la condición de objetores, $y$, en su caso, de las actividades convalidables; en la actividad de clasificación de los mismos; y en la creación de plazas y asignación de objetores. En cambio, prácticamente se omitió toda labor inspectora de cómo se estaba cumpliendo la prestación.

Una mención hay que hacer también a la política de $D$ efensa. En 1991, después de un amplio debate social y político, se llegó a la conclusión, prácticamente de forma unánime por las Cortes, de que no era posible conseguir unas Fuerzas Armadas enteramente profesionales. Lo decidido fue un Ejército que contara con profesionales y militares de reemplazo al $50 \%$. En este sentido, propuestas hechas en campañas electorales, como la del partido CD S postulando la supresión del servicio militar, se con- sideraban inviables. Sí, prosperó, en cambio, la idea de reducir la duración del servicio militar a 9 meses.

Por su parte, el M inisterio de D efensa, en un primer momento, no mostró excesiva preocupación por el problema en su aspecto cuantitativo, ya que en estos años, debido al aumento de la natalidad en los años 60, era muy grande el número de los jóvenes que formaban el contingente susceptible de ser llamado a filas. D e esta forma, la objeción de conciencia se contemplaba como un sistema de drenaje para extraer jóvenes de su llamamiento al servicio militar, ya que su número era muy superior al de las necesidades de las Fuerzas Armadas, evitando otro tipo de fórmulas, como la del excedente de cupo. No obstante, el M inisterio de D efensa empezaba a tomar conciencia del problema en su aspecto cualitativo, en cuanto que la objeción de conciencia suponía el cuestionamiento del papel social de las Fuerzas Armadas y de la necesidad de una política de D efensa16.

\section{La actuación de los órganos judiciales penales}

Los asuntos de insumisión dieron lugar a la intervención de otros agentes que indudablemente incidieron en el desarrollo de la política pública: los órganos legislativos y judiciales.

Como ya hemos dicho, en 1984 se regularon los delitos contra el deber de realización de la prestación social, castigados con penas privativas de libertad. Pero poco después, con motivo de la aprobación de un nuevo Código Penal M ilitar, se produjo una reforma de tales penas (Ley 0 rgánica 14/1985, de 9 de diciembre); y lo mismo ocurrió cuando en 1991 se aprobó la Ley 0 rgánica del Servicio M ilitar. M ediante tales reformas se redujo la duración de las penas y se trató de evitar la disparidad de las que correspondían a las conductas paralelas del servicio militar y de la prestación social.

M uchas de las personas a las que realmente iba dirigida la Ley, es decir, los verdaderos objetores de conciencia, optaron por la insumisión, como una forma de presión y estrategia de lucha, una desobediencia civil activa. Así, en un primer momento pre valeció la insumisión por motivos religiosos e ideológicos (Testigos de Jehová y M ovimiento de O bjeción de Conciencia), solucionándose en buena parte los problemas que ello planteaba con la «amnistía» de 1989 (M J, 286).

Sin embargo, cuando los asuntos de insumisión comenzaron a llegar ante los tribunales, diversos jueces reaccionaron dictando sentencias absolutorias o con penas meramente simbólicas (por ejemplo, apreciando la eximente total o incompleta de estado de necesidad), sentencias de las que se hacían amplio eco los medios de comunicación, creando la impresión de que la Ley no se cumplía, con la consiguiente deslegitimación del sistema17. 


\section{El abordamiento del problema entre 1993 y 1996}

\section{Los problemas}

Los problemas más acuciantes que se presentaban en 1993 eran los siguientes:

- Gran número de objetores, sin parangón en ningún otro país. En el año 1993 la situación había llegado ya a un punto crítico. El número de objetores había sufrido un aumento espectacular, tanto en términos absolutos como relativos. En ese año, en efecto, el porcentaje de objetores sobre el contingente militar anual era del $32,5 \%$, y en algunas Comunidades Autónomas, como el País Vasco y Navarra, más del $50 \% 18$.

- El M inisterio de Justicia estaba desconcertado, primero por la no aceptación del sistema por las personas a las que realmente iba dirigido; y luego por el incesante crecimiento del número de objetores, que desbordaron todas las previsiones más pesimistas, con un perfil que no coincidía con el previsto.

- Enorme retraso en la colocación de los objetores: había muchas menos plazas que objetores ( 3 objetores por plaza existente), así como diferencias geográficas de distribución, dando lugar a un gran lapso de tiempo entre el reconocimiento del objetor y su llamamiento efectivo, con las quejas consiguientes 19 .

- El problema empezaba a calar en la sociedad y en los me dios de comunicación. H asta entonces, el llamamiento para realizar la prestación constituía una posibilidad re mota, que afectaba a unos pocos objetores. Pero entre 1992 y 1993 los llamamientos comenzaron a afectar ya a muchos, con la peculiaridad de que la situación de gran parte de ellos era noticiable, haciéndose los medios de comunicación eco de ello: llevaban varios años esperando, tenían un trabajo e incluso cargas familiares, etc.

- Escasos medios personales y materiales del Ministerio de Justicia para hacer frente al problema, dificultando el desarrollo de una política eficaz ${ }^{20}$.

- Deslegitimación, tanto institucional como por los resultados, del sistema, por el rechazo ideológico21 y la falta de eficacia de la Administración. Muchas de las actuaciones de los jueces penales suponían un cuestionamiento de las bases legales del problema. La deslegitimación so- cial se amplió con el argumento - en una época en la que el índice de paro laboral era muy alto- de que los objetores estaban ocupando puestos de trabajo, por lo que la creación de plazas para realizar la prestación constituía un acto de insolidaridad con los desempleados (M) , 132). A ello se unía la falta de eficacia del M inisterio de Justicia ante el problema, lo que contribuía a alimentar a éste, pues la creencia de que el reconocimiento como objetor equivalía a una exoneración total de obligaciones de todo tipo constituía un incentivo para que los jóvenes se declarasen objetores de conciencia.

- Los problemas empezaron a afectar al M inisterio de De fensa incluso en el aspecto cuantitativo, dada la extensión que adquiría el fenómeno de la objeción, máxime cuando se comenzaron a notar las consecuencias de la reducción de la natalidad, poniendo en peligro la integridad del contingente militar.

\section{Las posibles soluciones}

En estas circunstancias, tanto el M inisterio de D efensa como el de Justicia sintieron la necesidad de actuar porque el sistema hacía aguas por todas partes. En un plano teórico, las posibles soluciones eran las siguientes:

- Reducir el número de objetores, para lo cual habría que actuar en la fase de reconocimiento, aumentando los re quisitos para ello;

- aumentar las exenciones y aplazamientos, con el peligro de crear discriminaciones con el servicio militar y, sobre todo, de un aumento de la bolsa de objetores, derivando los casos del servicio militar a la objeción;

- aumentar el número de plazas y el nivel de exigencia de la prestación, a fin de reducir el atractivo que ésta suponía frente al servicio militar.

Surgieron entonces discrepancias entre los M inisterios de Justicia y de D efensa22: éste pretendía un endurecimiento de los requisitos para el reconocimiento de la objeción, así como del régimen de la prestación, a fin de evitar el trasvase de personas desde el servicio militar a éste. Para ello proponía incluso el cambio legal, en el sentido de permitir la declaración de objeción sólo hasta el momento anterior a la asignación de destino, ya que se había constatado que muchos jóvenes esperaban a conocer éste para, si no les satisfacía, declararse objetores.

Sin embargo, el plan definitivamente aprobado el 11 de mar$z 0$ de 1994 descartó no sólo la modificación legislativa, sino incluso el tratar de incidir sobre el reconocimiento de la condición de objetor. En concreto, se basaba en los siguientes puntos (M), 219-236): 
- Creación de una Dirección General autónoma, agrupando los órganos que actuaban en la materia y añadiendo una nueva Subdirección General de Inspección.

- Aumento de los medios personales y materiales adscritos a esa Dirección General, concretándose en un importante incremento de los puestos de trabajo, así como en una transferencia de crédito de 8.000 millones de pesetas.

- D escentralización de determinadas funciones en favor de las D elegaciones del Gobierno, así como de las Comunidades Autónomas, mediante convenios con éstas.

- Aumento del número de plazas concertadas, con especial atención a la Administración en cuanto generadora de puestos.

- Plan extraordinario de incorporación de objetores, de manera que quedaran cubiertas todas las plazas disponibles, proveyendo a tal efecto las plazas dotadas con alojamiento y manutención, incluso mediante la movilidad geográfica de los objetores. En concreto, se preveía que estuvieran obligados a desplazarse 7.000 objetores en 1994 y 10.000 en 1995, a cuyo fin se destinaría la mitad del crédito de 8.000 millones; asimismo, se preveía la posibilidad de incorporar forzosamente a los objetores en las plazas existentes o que se pudieran crear.

- Aumento de las inspecciones, a fin de lograr un cierto endurecimiento de la prestación, pero con el temor de que ello provocara el aumento de los abandonos y de la insumisión.

- Aprobación de un nuevo Reglamento, a fin de unificar todo el régimen de la objeción de conciencia y de la prestación social, evitando ciertos problemas derivados del excesivo paralelismo del régimen de la prestación con respecto al del servicio militar.

Con todo ello se pretendía dar una cierta seriedad a la prestación y poner fin a la enorme bolsa de objetores pendientes de la prestación. En concreto, se preveía que en 1994 realizaran la prestación 35.000 objetores (con lo que se absorberían los objetores reconocidos en 1991 y 1992); en 1995, 50.000 (los reconocidos en 1993 y primer semestre de 1994); de forma que en 1996 pudieran ser llamados todos los objetores reconocidos durante el segundo semestre de 1994 y 199523.

\section{Los resultados del plan}

¿C uáles fueron los resultados del plan? C omo veremos a continuación, fueron muy escasos, tanto por el propio contenido del plan como por la falta de voluntad política de aplicarlo por parte del M inisterio de Justicia.

\section{El continuo aumento del número de objetores}

El plan, como hemos visto, renunció a actuar sobre la variable fundamental del problema: el reconocimiento prácticamente automático de la condición de objetor de quien se declaraba como tal, con el argumento de que el Consejo $\mathrm{N}$ acional de $\mathrm{Ob}$ jeción de Conciencia era un órgano independiente24).

Como consecuencia, el número de declaraciones siguió aumentando y lo mismo el de reconocimientos. En esta época pre valece ya claramente la objeción de conveniencia25, haciéndose el perfil del objetor cada vez más parecido al perfil general de losjóvenes afectados (M I, 167-169). Es muy significativo que empezara entonces a aumentar espectacularmente el número de declaraciones de objeción de personas menores de 18 años26. Los propios interesados reconocían (no, evidentemente, en las solicitudes dirigidas a la Administración, que se atenían formal mente a lo legalmente previsto) que los motivos reales por los que se de claraban objetores no eran los legalmente previstos, sino la propia conveniencia27. Lo más llamativo era que estas manifestaciones se hacían con toda naturalidad, con la conciencia de estar haciendo algo legítimo, es decir, con la consideración de que la objeción no era una opción subsidiaria del servicio militar, sino alternativa.

\section{La nueva estructura administrativa y el aumento de recursos económicos}

Por lo que se refiere a la previsión de una Dirección General exclusiva para la O bjeción de Conciencia, independiente de los Asuntos Religiosos, se creó inmediatamente, por Real Decreto 494/1994, de 17 de marzo, integrando dentro de ella, como Subdirecciones $\mathrm{G}$ enerales, a la Secretaría del Consejo $\mathrm{N}$ acional de 0 bjeción de Conciencia y a la O ficina para la Prestación Social, y creando una nueva Subdirección General para la inspección y asuntos administrativos. Curiosamente, el Director $G$ eneral que había preparado el plan de objeción pasó a desempeñar otra Dirección G eneral distinta. Es decir, quien iba a ejecutar el plan era un nuevo D irector General, distinto de quien lo había promovido, lo que es muy revelador de las escasas esperanzas que se ponían en la ejecución de dicho plan.

Asimismo, se produjo un considerable aumento de los créditos presupuestarios en este periodo. Así, el presupuesto de 1994 fue superior al doble del de 1993; y los de 1995 y 1996 fueron de 3.716 millones de pesetas (1.100 más que el de 1994) (MJ, 172-174).

N o obstante, la falta de agilidad continuó manifestándose en diversos aspectos administrativos (retrasos en la resolución de solicitudes y recursos, demoras en el pago de haberes y de vales de vestuario, etc.), lo que provocaba continuas quejas de los afectados28. 


\section{Las modificaciones normativas y su aplicación práctica}

Por Real Decreto 266/1995, de 24 de febrero se aprobó un nuevo Reglamento, en el que se regularon conjuntamente la objeción de conciencia y la prestación social sustitutoria.

Una de las principales innovaciones del nuevo Reglamento fue la relativa al régimen de las exenciones y aplazamientos, estableciendo un régimen mucho más favorable para quienes se habían declarado objetores que para quienes estaban sometidos al Reglamento de Reclutamiento Militar. Se pueden citar numerosos ejemplos en este sentido: en el régimen de la prestación se podían solicitar aplazamientos por sostenimiento familiar después de haber disfrutado de otros aplazamientos, cosa que no se podía en el régimen del servicio militar; en el régimen de la prestación se contemplaban prórrogas inexistentes en el del servicio militar, como la de figura relevante en el ámbito artístico; una regulación más ventajosa en las prórrogas por elección popular; la posibilidad de manifestar la preferencia para incorporarse hasta los 24 años (22 en el régimen del servicio militar).

La consecuencia era obvia: para quien tuviera un mínimo de información (y no hay que olvidar que ya en esta época los servicios de Juventud de los Ayuntamientos, Diputaciones y Comunidades Autónomas operaban a pleno rendimiento, aś como la existencia de numerosas asociaciones juveniles, oficinas de información juvenil, etc.) y pretendiera obtener una exención o aplazamiento, le era mucho más efectivo declararse objetor y, a continuación, pedir esa exención 0 aplazamiento que hacerlo directamente sin declararseobjetor. Es decir, el propio Reglamento estaba incentivando a los jóvenes para que se declarasen objetores.

Del mismo modo, el nuevo Reglamento contemplaba un ré gimen de la prestación en la situación de actividad mucho más beneficioso que el del servicio militar. Aś, los militares de reemplazo se encontraban en situación de disponibilidad permanente para el servicio; frente a ello, quienes realizaban la prestación tenían un horario semanal de 35 a 40 horas semanales, además de disfrutar de un régimen mucho más favorable en materia de permisos y vacaciones. $Y$, además, quienes realizaban el servicio militar, como consecuencia del carácter jerarquizado y armado del Ejército, se encontraban sometidos a disciplina militar (mucho más exigente que la que operaba sobre quienes realizaban la prestación), con restricciones en los derechos fundamentales, con un sistema de sanciones disciplinarias mucho más riguroso (que incluía la privación de libertad), y con limitaciones en las garantías procedimentales.

Y si del aspecto normativo se pasaba al plano de la realidad de los hechos, el régimen de los objetores era aún más beneficioso. En efecto, todo hace pensar que en la práctica la D irección General de 0 bjeción de Conciencia era mucho más flexible a la hora de conceder exenciones y aplazamientos que el M inisterio de D efensa, pues mientras éste necesitaba no disminuir excesivamente su bolsa de jóvenes, aquélla tenía el problema totalmente opuesto, reducir en lo posible la bolsa de objetores pendientes de la prestación.

Por lo que se refiere a la situación de actividad, no era sólo que el nivel de exigencia en la prestación fuera en la práctica muy inferior, sino que, en muchos casos, permitía seguir llevando un ritmo normal de vida, que indudablemente hubiera cambiado de tener que haber realizado el servicio militar, que en muchos supuestos lo primero que implicaba era el ser destinado a un lugar lejano al de residencia22. Por poner un ejemplo, la tarea de levantar y acostar a una persona inválida a primera hora de la mañana y por la noche, o la de abrir un colegio un par de horas por la tarde para realizar actividades extraescolares, podían tener una gran utilidad social, con amplia satisfacción para los propios objetores y para los servicios competentes, pero el interesado realizaba esta tarea y el resto del día podía seguir su régimen habitual de vida (trabajar, estudiar, mantener su forma de vida habitual, etc.), ya que en el $98 \%$ de los casos la prestación se realizaba en la población de domicilio del objetor. Es decir, muy pronto se extendió la idea de que el régimen de la prestación era mucho más favorable para los afectados que el del servicio militar.

A este respecto, es paradigmático el derecho al abono de gastos de vestuario: el $M$ inisterio de Justicia entregaba al objetor un cheque para que pudiera ser gastado en unos grandes almacenes en ropa u otro material, que no tenía por qué guardar relación alguna con el contenido o las necesidades de la prestación, ya que normalmente ésta no exigía un vestuario especial (M), 127, 134, 180). Ello sin duda constituía un incentivo, en perjuicio del servicio militar, para declararse objetor. Durante mucho tiempo el propio M inisterio de Justicia justificó este beneficio con el argumento de la analogía con el servicio militar.

\section{La descentralización de la prestación}

Por lo que se refiere a la descentralización de la prestación, no se observaron resultados tangibles, con independencia de que esto era algo que no tenía mucha relación con la problemática de fondo. Realmente la Comunidad Autónoma que había firmado un concierto operaba como una entidad más, al igual que podía hacerlo un Ayuntamiento o una entidad privada. Es decir, no se transfirieron a las Comunidades Autónomas competencias propias del Ministerio de Justicia. Y es que parece que no fue más que una forma de «vender» el plan a las Administraciones autonómicas a fin de conseguir que éstas aumentasen el número de plazas.

Por lo demás, no hubo un especial interés en la materia por parte de las Comunidades Autónomas. Es muy significativo que, a partir de este periodo, éstas ni siquiera mencionaran, en las Le 
yes que aprobaban, la prestación social como al go de lo que pudieran obtener beneficios, a pesar de ostentar competencias en los sectores en los que podían actuar los objetores. Así, las nuevas normas que se iban aprobando sobre Protección Civil (por ejemplo, la Ley catalana de Protección Civil 4/1997, de 20 de mayo) o sobre prevención y extinción de incendios forestales (por ejemplo, la Ley catalana 5/1994, de 4 de mayo o la madrileña 14/1994 de 18 de diciembre), e incluso sobre Servicios Sociales (por ejemplo, la Ley valenciana 5/1997, de 25 de junio), contemplaban el voluntariado, pero no la prestación social, lo cual era demostrativo del gran fracaso en la credibilidad de ésta y de la labor de los objetores en los sectores en que debían actuar.

\section{El aumento del número de puestos para realizar la prestación social}

Por lo que se refiere al número de puestos de actividad, ciertamente se produjo un notable aumento, pero en todo momento fue por detrás del aumento del número de objetores. Así, si la Subsecretaria de Justicia manifestaba en diciembre de 1993 que había 3 objetores pendientes por cada plaza concertada30, el Director General el 23 de febrero de 1994 manifestaba que el número de objetores pendientes (115.779) superaba en más de 4 al de plazas existentes (26.788). Por tanto, cabe dudar de la eficacia de estos resultados.

Pero además el aumento se tradujo, en unos casos, en un aumento de la desorganización; y, en otros, en la creación de plazas sin un verdadero contenido31. $H$ ay que tener en cuenta que la estructura de muchas de las entidades privadas era muy endeble, ya que éstas carecían de infraestructura suficiente, o estaban pensadas para voluntarios que ofrecían sus servicios durante un escaso número de horas, o dirigidas por voluntarios a los que la incorporación de un importante número de objetores les desbordaba completamente, o incluso tenían un funcionamiento intermitente, en función de las subvenciones que iban recibiendo. En el mejor de los casos tenían contratado un empleado, normalmente con jornada reducida y dependiente de la concesión de la correspondiente subvención finalista. En estas circunstancias, difícilmente podían asumir varios objetores, máxime teniendo en cuenta que el M inisterio de Justicia sólo realizaba conciertos cuando la entidad estaba dispuesta a asumir más de tres objetores, de tal forma que, si ya era difícil organizar las actividades de un objetor, aún más difícil era hacerlo con tres o más.

Asimismo, se pudo observar que determinadas medidas dirigidas a incentivar la creación de plazas tuvieron un efecto no de seado. Así, por ejemplo, la concesión de subvenciones a las entidades privadas dedicadas a servicios sociales se condicionó - 0 , en su caso, se estableció como criterio preferente- a la firma del correspondiente concierto para que en ellas se pudiera realizar la prestación32. Ello llevó a que muchas de estas entidades, carentes de un mínimo de infraestructura de personal y medios, firmaran conciertos, recibiendo objetores a los que luego era incapaces de asignar tareas, provocando problemas organizativos.

Por lo que se refiere a las entidades públicas, se fue haciendo más patente el dato de que las creaciones y ampliaciones de plazas sehacían no en función de las necesidades reales de atención a los fines de interés general, sino como una medida de apoyo al obje tor y a sus familias, especialmente cuando surgió la amenaza de que aquéllos podían ser desplazados a otras localidades para hacer su prestación en caso de falta de plazas en la localidad de su residencia. Esto fue especialmente visible en determinadas Ayuntamientos y Diputaciones, especialmente cuando quien promovía el concierto eran las Áreas de Juventud de tales entidades33.

El sistema tenía un defecto de base, y es que no daba importancia a los bajos rendimientos de la prestación social. Las entidades no tenían problema, porque, donde geográficamente había objetores, la oferta de éstos era prácticamente ilimitada, por Io que la cantidad paliaba la falta de calidad. EI M inisterio de Justicia tampoco daba mayor importancia a esta cuestión, porque consideraba que el aumento de la cantidad de objetores en las entidades suponía reducir la bolsa de objetores pendientes, y además entendía que era al go que no le concernía, sino a la entidad en cuestión. Pero lo cierto es que ello redundaba a la baja con respecto a las entidades, pues los objetores al egaban agravios comparativos, y daba lugar a peticiones de traslado desde las entidades con un nivel de exigencia mayor a las de un nivel inferior, con la agravante de que el M inisterio de Justicia, a la hora de tramitar esas peticiones de cambios de destino, daba prevalencia al interés del objetor por encima del interés de la entidad a la que había sido destinado, primando así, de hecho, a las entidades con peor funcionamiento y menor nivel de exigencia.

$\mathrm{H}$ ay que destacar también que, con respecto a las plazas de al ojamiento y manutención, no sólo no se crearon nuevas plazas, sino que además fueron desapareciendo las pocas que existían, como luego veremos.

\section{La actitud de los objetores ante la prestación social}

M uchos de los objetores no dieron la respuesta adecuada a las necesidades de las entidades que pretendieron obtener una rentabilidad social de la prestación.

A ello contribuyó un dato, relacionado con el perfil de los objetores que realizaban la prestación. Entre éstos predominaban personas de cierta edad, con obligaciones laborales e incluso familiares. En consecuencia, hubo una tendencia por parte de éstos a negociar su situación, en el sentido detratar de conseguir ventajas en horario (más reducido, horarios especiales, etc.), con el fin 
de mantener sus anteriores actividades. D e esta forma, la prestación dejaba de constituir la actividad principal del objetor, y pasaba a ocupar el tiempo que, en otras circunstancias, el interesado hubiera dedicado al ocio. H ubo entidades que aceptaron esta situación, pero otras no lo hicieron, con el consiguiente choque.

De esta forma, apareció el objetor desmotivado, con una actitud muy poco activa, e incluso pasiva34, que no planteaba problemas de oposición directa, pero sí de pasotismo y de cumplimiento de horarios, con vicios similares a los que se producían en el servicio militar, tales como el escaqueo. Tal actitud sorprendió a muchos, precisamente por no caer en la cuenta de la diferente actitud con la que se enfrentaban a la realización de tareas los empleados y voluntarios de las entidades por un lado y los objetores por otro. En efecto, en un primer momento, las entidades, en especial las privadas, pensaron en el objetor como un voluntario más. Pero ello suponía confundir el contenido de la actividad con el fundamento de la misma: ciertamente el objetor y el voluntario realizaban idénticas actividades, pero mientras uno lo hacía por su propia voluntad, el otro lo hacía con carácter forzoso, agravada esta circunstancia por la ausencia real, como antes hemos dicho, de una verdadera objeción de conciencia, al predominar la objeción de conveniencia.

Esta actitud confundió a los responsables de tales entidades y en ciertas ocasiones dio lugar a choques entre los objetores y los profesionales y voluntarios, mucho más concienciados por su propia natural eza35, Ilegando ciertas entidades incluso a rescindir el concierto, al comprobar que los objetores causaban más problemas que los que resolvían36.

Asimismo, en ciertas entidades se pudo apreciar una resistencia de sus empleados a aceptar a los objetores, bien por motivos ideológicos (por entender que venían a ocupar puestos que correspondían a empleados), bien simplemente porque la organización de la actividad de los objetores suponía una tarea añadida a los encargados de la misma, dándose no pocos casos de desentendimiento del tema.

Todas estas circunstancias dieron lugar a una situación generalizada de incumplimientos de los horarios e incluso de falta de ocupación efectiva, traduciéndose en una gran falta de eficacia en su actuación.

Esta ineficacia quedó patente, por ejemplo, en el verano de 1994, en el que se produjeron numerosos incendios forestales, quedando desbordadas las Administraciones competentes y te niendo que pedir ayuda al Ejército, mientras había varios miles de objetores inactivos, provocando las consiguientes críticas37.

Esta situación era problemática, porque contribuía a alimentar el sistema: las entidades que pretendían dar una cierta serie dad a la prestación tenían que luchar contra las alegaciones de agravios comparativos, formuladas por objetores ante el evidente trato favorable de muchas entidades a los suyos, lo que a su vez provocaba la petición de cambios de destino de los objetores a las entidades con menor nivel de exigencia. Y, por otra parte, ello contribuía también a que se fuera corriendo la voz de que era más cómodo hacer la prestación social que el servicio militar, con el consiguiente aumento del número de declaraciones de objetor.

\section{Los esfuerzos por obtener el máximo rendimiento de los puestos concertados}

Por lo que se refiere al plan de incorporación de objetores, también tuvo sus problemas. La primitiva decisión de cubrir totalmente las plazas existentes fracasó. En primer lugar, por la no coincidencia de ubicación geográfica entre la bolsa de objetores y la bolsa de puestos. En unos lugares siguieron sobrando obje tores y en otros siguieron sobrando plazas. La idea de movilizar a los objetores mediante plazas dotadas con alojamiento y manutención no se llegó a aplicar. Primero, por la presión de los propios objetores afectados, que hicieron lo posible por no moverse de sus lugares de origen, sin que existiera una voluntad política de imponer coactivamente tal movilización. Segundo, porque las cantidades pagadas en concepto de alojamiento y manutención por el Ministerio de Justicia eran claramente insuficientes38. En efecto, en el servicio militar existían cuarteles que facilitaban el alojamiento de la tropa. Pero en la prestación no existía un sistema de alojamientos colectivos, dada la dispersión de programas y de puestos de actividad, lo que significa que se tenían que buscar alojamientos privados, para los cuales las asignaciones económicas previstas a tal fin eran insuficientes. Por cierto, una prueba más de la escasa utilidad que las propias entidades atribuían a la prestación lo constituye el dato de que muy pocas estuvieran dispuestas a organizar un sistema propio de alojamiento 0 a sufragar los correspondientes gastos.

En estas circunstancias, al cabo de unos años, estas plazas con alojamiento y manutención prácticamente habían desaparecido 0 eran ocupadas por personas de la misma localidad que realmente no utilizaban el alojamiento ofrecido. Así, el examen de la bolsa de puestos del año 1997 muestra que apenas había entidades que ofrecieran este tipo de plazas, y muy pocas eran las poblaciones en las que se ofrecía este régimen; predominando en las plazas situadas en el extranjero. Por tanto, la pretendida movilidad geográfica de los objetores constituyó un rotundo fracaso.

Idéntico fracaso se observó en el aspecto de evitar el desfase temporal entre la bolsa de objetores y las plazas vacantes. Tal desfase temporal se debía, en gran parte, al sistema de llamamientos, pues se seguía un régimen similar al del servicio militar. Así, en 1993 y 1994 se hicieron dos llamamientos anuales, y 4 (de hecho, 3) en 1995 (MJ, 199). De esta forma, ocurría que, licenciado un objetor que había ocupado una plaza, ésta quedaba vacante durante varios meses, hasta que se incorporaba un nuevo 
objetor, de modo que, cuando la plaza tenía una utilidad social, se había creado una necesidad social y sin embargo se dejaba de prestar el servicio, con las consiguientes quejas de las entidades.

También se produjeron desequilibrios en lo referente al perfil de objetor requerido: el M inisterio de Justicia realizaba una asignación indiscriminada de objetores a los programas y entidades, ocurriendo en muchas ocasiones que el objetor asignado a una entidad no encajaba en el perfil de una plaza (por ejemplo, al incorporarse para realizar tareas administrativas una persona que apenas sabía leer y escribir), problema éste al que el M inisterio no podía dar solución ante la masificación del sistema y, quizás, también, para evitar tratos discriminatorios. A ello había que añadir el problema de los objetores a los que nadie quería, bien por su escaso nivel cultural, bien por circunstancias concretas (personas con determinados antecedentes, conocidos en el ámbito de la entidad), bien por pertenecer a determinadas etnias.

\section{Las actuaciones para conseguir la seriedad de la prestación}

Por lo que se refiere al aumento de las inspecciones y al endurecimiento de la prestación, ello no se tradujo en la adopción de medidas serias. Lo que prevaleció fue la idea de crear plazas a toda costa, aun a sabiendas de su escaso contenido, por lo que de las actuaciones inspectoras no se dedujeron muchas consecuencias prácticas. En este sentido, no hay constancia de que en la época se extinguiera el concierto con ninguna entidad por falta de contenido de las plazas, tal como autorizaba el Reglamento de la Prestación Social. Pero es que además la idea preval ente en la D irección $G$ e neral de 0 bjeción de Conciencia era la de una interpretación be neficiosa para el que realizaba la prestación, con olvido de que ello podía incidir en una disminución de la utilidad social. Y aś se concedían los aplazamientos, los cambios de destino, permisos, etc., sin subordinación a las necesidades del servicio, en detrimento de los intereses de las propias entidades en las que los objetores estaban prestando o iban a prestar sus servicios, lo que incidía en que se asignara a éstos tareas accesorias, muchas veces de muy escaso contenido, precisamente para evitar que quedara en sus manos la puesta en práctica de las actividades39.

A ello se unía que el régimen disciplinario legalmente previsto no era nada disuasorio (MJ, 284). En efecto, la sanción de pérdida de retribución (1.500 pesetas) más bien movía a la hilaridad; y la sanción de cambio de adscripción era inoperante en la práctica, dada la falta de plazas con alojamiento que permitieran un cambio no sólo de entidad, sino de lugar de geográfico de prestación. Sólo la prolongación de la prestación podría tener cierta eficacia, pero, por razones obvias, las propias entidades no estaban interesadas en esta clase de sanción, que les obligaba a soportar aún más tiempo a objetores incómodos.
A ello hay que añadir la dificultad de desentrañar el significado de la prohibición legal de que los objetores «desempeñaran un puesto de trabajo». La Ley establecía que la asignación de trabajos y funciones a los objetores no debía incidir negativamente en el mercado de trabajo. Precisamente la imputación de que los objetores realmente estaban ocupando puestos de trabajo que podrían ser desempeñados por personas en paro contribuía enormemente a deslegitimar estas actividades, lo que obligaba a los responsables de la prestación a hacer referencia, cuando se creaban puestos de actividad, a que ello no supondría supresión de puestos de trabajo. Lo inconcreto de la norma, además, dio lugar a que las entidades, sobre todos las públicas, no tuvieran las ideas muy claras, con el consiguiente temor a enfrentarse con los sindicatos y con los propios objetores, lo que provocó que la prestación tuviera un contenido aún menor.

Los resultados últimos fueron obvios. No hubo realmente un endurecimiento del régimen de la prestación social, ni un excesivo aumento de su rentabilidad social. Y, en consecuencia, para los jóvenes seguía siendo mucho más rentable elegir la vía de la obje ción sobre la vía del servicio militar, y por ello el número de obje tores siguió creciendo. La bolsa de objetores pendientes de realizar la prestación social no sólo no disminuyó, sino que siguió aumentando. La actuación de la D irección General de O bjeción de Conciencia en este periodo puede cal ificarse de clamoroso fracaso 40.

\section{Las actuaciones de otros actores: los órganos judiciales}

Unos actores con gran incidencia en el desarrollo de la política pública fueron los tribunales, especialmente los penales, encargados de juzgar los delitos de insumisión. Q uizá lo más llamativo en este punto fue la falta de un criterio uniforme de tales órganos. Así, mientras unos se limitaban a aplicar las penas establecidas en la Ley, otros buscaron todo tipo de subterfugios para evitar la imposición de las penas privativas de libertad. Al efecto se utilizaron numerosos razonamientos, la mayor parte de ellos muy discutibles (eximente completa o incompleta de ejercicio de un derecho, error de prohibición, estado de necesidad, causa de justificación por no haber resuelto la Administración en plazo, propuesta de indulto, planteamiento de cuestión de inconstitucionalidad con la consiguiente paralización del procedimiento entre tanto; etc.) (M J, 286-289). Sólo un 60\% de las sentencias era condenatoria, lo que demuestra también la escasa sintonía de la legislación con lo que pensaban los jueces.

O bviamente, los medios de comunicación se hicieron amplio eco de estas diferencias de criterio y de esas sentencias muchas de ellas Ilamativas41.

En 1995 las Cortes Generales aprobaron un nuevo Código Penal, que modificó las penas de los delitos relativos a la prestación social, suprimiendo las de privación de libertad, y sustitu- 
yéndolas por la de inhabilitación absoluta de 8 a 12 años y multa de 12 a 24 meses. La modificación tenía gran importancia. Por un lado, hacía perder virulencia a los movimientos anti-objeción frente a la opinión pública, ya que era mucho menos llamativa una condena a inhabilitación que a la privación de libertad. Además, cabía esperar que los propios jueces pondrían menos inconvenientes a la aplicación de las nuevas penas. Pero frente a ello el cambio supondría un aumento cuantitativo de la insumisión, ya que las penas en cuestión no tenían un excesivo carácter desincentivador de ésta.

Sin embargo, no se produjo modificación análoga para los delitos similares de los obligados al servicio militar, que continuó siendo de 6 meses a 2 años de prisión e inhabilitación absoluta de 10 a 14 años, en tiempo de paz. De esta forma, apareció un nuevo incentivo para escapar del régimen del servicio militar y entrar en el de la objeción. En efecto, si una persona no quería realizar ningún tipo de servicio (por ejemplo, por estar trabajando) y se veía en la opción de elegir entre una pena de cárcel y una pena que le impedía trabajar para la Administración o recibir ayudas de ésta, la elección era clara: declararse objetor, aunque no tuviera intención de realizar luego la prestación social. Pero aś se sobrecargaba a los órganos del M inisterio de Justicia con actuaciones relativas a personas que realmente no estaban dispuestas a hacer ningún tipo de prestación social.

Ello, además, supuso una importante modificación del perfil del objetor que accedía a los tribunales penales. En efecto, como consecuencia de la supresión de penas privativas de libertad, apareció el perfil del insumiso de conveniencia: una persona que no deseaba realizar ni el servicio militar ni la prestación social, pero no por motivos de conciencia, sino simplemente porque ante el balance coste beneficio de tener que hacer la prestación social o no hacerla (por un lado, posibilidad de pérdida del trabajo o de los estudios; por otro lado, unas penas que simplemente le ímpedían obtener ayudas de la Administración o trabajar para ésta), optaba por esto último. El joven, siendo consciente de que sus actos podían ser sancionados, asumía el riesgo de forma personal eindividual, pero sin ningún tipo de connotación política o ánimo reivindicativo (MJ, 285).

Por lo demás, la pena de inhabilitación no pasaba de ser una pena teórica en la mayor parte de los casos, ya que sólo afectaba a quien tuviera intención de solicitar subvenciones 0 pretendiera trabajar para las Administración, o para entidades 0 empresas públicas.

\section{El desarrollo de otras políticas que incidieron en la objeción de conciencia y en la prestación social}

Simultáneamente el M inisterio de D efensa estaba desarrollando una política de modificación normativa, dirigida a hacer más atractivo el servicio militar mediante una serie de mejoras en la prestación del servicio militar (menor duración, mayor calidad de vida, regionalización, establecimiento de una tabla de derechos, etc.). En este sentido, se aprobó un nuevo Reglamento de Reclutamiento (Real Decreto 1107/1993, de 9 de julio), aś como un Reglamento del Servicio Militar (Real Decreto 1410/1994, de 25 de junio). Junto a ello se desarrolló una amplia campaña publicitaria.

Sin embargo, a pesar de que durante el primer semestre de 1994 el M inisterio de D efensa tuvo algún motivo para la esperanza, lo cierto es que duró muy poco, porque el número de de claraciones de objeción siguió creciendo de manera imparable.

Por otro lado, ante las inesperadas dificultades encontradas, los poderes públicos empezaron a estudiar otras vías alternativas para conseguir la legitimación del sistema y que sirvieran también para descargar en lo posible la bolsa de objetores. En concreto, se pensó en el servicio civil y en el voluntariado. Ahora bien, ello suponía un cambio radical de filosofía, ya que eran totalmente diferentes una prestación social sustitutoria del servicio militar, fundada en el art. 30.2 de la Constitución, y un servicio civil para fines de interés general y desligado del servicio militar, fundado en el art. 30.3 de la N orma Suprema.

Por lo que se refiere al voluntariado, las Cortes aprobaron la Ley 6/1996, de 15 de enero, del Voluntariado, patrocinada por el M inisterio de Asuntos Sociales. Esta Ley - cuyo ámbito de aplicación en principio era muy limitado, pues el voluntariado es una materia en la que predominantemente ostentan competencias las Comunidades Autónomas- se dictó con la clara finalidad de ayudar a vaciar la bolsa de objetores pendientes. Lo realmente importante - y lo más novedoso de la Ley - era la posibilidad del reconocimiento de los servicios voluntarios a efectos de su convalidación por el tiempo de duración de la prestación social. Estos beneficios se podían extender a los voluntarios que participaran en programas que desarrollasen actividades de competencia de las Comunidades Autónomas o de los entes locales.

La Ley supuso un cambio total de filosofía con respecto al servicio militar y a la prestación. Hasta entonces se consideraba, al menos en el plano jurídico, que existía una obligación principal (el servicio militar) y otra subsidiaria (la prestación social). A partir de la aprobación de la Ley cabía eximirse de la obligación subsidiaria (y no de la principal, lo que resultaba bastante contradictorio) mediante la realización del voluntariado.

Por otro lado, hubo evidentes incoherencias en la actuación de otros poderes públicos en lo referente al tratamiento de la objeción y del servicio militar. Así, es muy Ilamativo que las leyes y reglamentos permitieran que los objetores - que por definición eran contrarios al uso de las armas- pudieran presentarse a pruebas selectivas para cubrir plazas de Cuerpos armados como la policía local 0 autonómica, e incluso el Cuerpo Nacional de 
Policía (Real D ecreto 1593/1988, de 16 de diciembre, e, implícitamente, el Real Decreto 614/1995, de 21 de abril), limitándose a exigir un mero compromiso de portar armas y, en su caso, llegar a utilizarlas42.

Asimismo, hay que destacar la actuación de deslegitimación del sistema en la que continuaban los movimientos de objeción, pacifistas, etc. En este sentido, una operación como el envío de varios objetores a Bosnia, con una clara intención propagandística por parte del M inisterio de Justicia, fue un fracaso en este aspecto, pues los objetores allí destinados firmaron un comunicado contra el servicio militar y la prestación social y en favor de la excarcelación de los insumisos43.

\section{La situación creada a partir de 1996}

\section{Las nuevas coordenadas de 1996: la profesionalización de las Fuerzas Armadas}

En 1996 se convocaron elecciones generales y en los diferentes programas electorales apareció con carácter destacado la cuestión del servicio militar y la objeción de conciencia. EI PSOE proponía reducir la duración de la prestación social para igualarla con el servicio militar. Propuesta que era políticamente absurda, porque, incluso a corto plazo, convertía en inviable el servicio militar, pues la única ventaja en gravosidad de éste sobre la prestación era, precisamente, su menor duración. Por ello, le hubiera sido mucho más rentable electoralmente proponer la supresión pura y simple del servicio militar. El Partido Popular, por su parte, proponía reducir el servicio militar a 6 meses y dar un sueldo a los soldados de reemplazo, sin especial mención a los objetores.

Sin embargo, el PP, para obtener el apoyo de otros grupos a su programa de gobierno, pactó con los partidos nacionalistas, en particular con CiU, y como consecuencia de ello, asumió el compromiso de suprimir a medio plazo el servicio militar obligatorio, renunciando a su propuesta electoral.

La decisión se adoptó sin estudios y sin ningún debate sobre las consecuencias que podría producir un cambio total del modelo de Fuerzas Armadas. Entre esas consecuencias estaban las que se producirían sobre la prestación social. En efecto, la supre sión del servicio militar obligatorio llevaba implícita la supresión de la objeción de conciencia a éstey, en consecuencia, el fin de la prestación social. Con lo cual esta política pública pasaba a tener una fecha de caducidad, dejando de ser un problema de dura- ción indefinida, para pasar a ser un problema con un plazo más o menos largo de duración. Ello implicaba un importante cambio de perspectiva. Ahora lo fundamental era llegar a ese fin de la forma más airosa posible, sin tampoco crear muchas expectativas con la prestación, para que, cuando ésta terminara, tampoco causara excesivos contratiempos.

\section{La situación en $\mathbf{1 9 9 6}$}

La situación había sufrido un agravamiento muy profundo con respecto a la existente en 1993:

- Progresivo aumento del número de objetores, con predominio absoluto de la objeción de conveniencia. Las declaraciones de objeción pasaron de 68.209 en 1993 a 93.279 en 1996. Los objetores reconocidos pasaron de 46.084 a 91.204.

- Aumento también del número de plazas, pero muy por detrás de las necesidades. Los puestos pasaron de 35.614 en 1993 a 66.514 en 1995. Como puede observarse, el número de plazas creadas seguía siendo inferior al de objetores, lo que significa que el objetivo principal de la política pública desarrollada hasta 1996 (poner fin a la bolsa de objetores pendientes de cumplir la prestación) había fracasado. Todo hace pensar, además, que la calidad de las plazas no era buena.

- Se había hecho un gran effuerzo en la colocación de objetores, pasando de 11.929 en 1993 a 54.139 en 1995, pero seguía existiendo una enorme bolsa de objetores pendientes de realizar la prestación. Así, en abril de 1996 había 130.325 objetores pendientes de incorporación no llamados, lo que implicaba un gran desfase temporal entre la fecha del reconocimiento como objetor y la de incorporación a la prestación (M J, 143).

\section{La actuación de los poderes públicos}

Ante la situación de hecho existente, se elaboró un plan de choque, aprobado el 24 de julio de 1996 (MJ, 237-255).

El plan fijaba, como objetivos generales, los de eliminar la acumulación de objetores pendientes de realizar la prestación, para que en 1998 se pudieran incorporar automáticamente a dicha prestación social; y garantizar un cumplimiento riguroso y eficaz para la sociedad.

Sin embargo, en el mismo plan se introducían una serie de limitaciones que hacían dudar acerca de la consecución de esos fines. En primer lugar, su ejecución no debía implicar aumento 
de los gastos públicos (hay que recordar que el PP Ilegó al Gobierno con un programa de austeridad presupuestaria). En se gundo lugar, se preveía un importante aumento de puestos, pero sólo donde se necesitaran, no porque hubiera más necesidades sociales, sino porque hubiera objetores: es decir, el criterio de la utilidad social de las plazas era el de que hubiera o no objetores para cubrirlas, convirtiéndose aśi la colocación de tales objetores en la pauta o canon de determinación de si había 0 no utilidad social.

Los objetivos concretos se cifraban en alcanzar, respectivamente, 90.000, 105.000 y 120.000 plazas en 1996, 1997 y 1998.

Se preveía abrir nuevas vías de colaboración, así como profundizar las ya existentes con Comunidades Autónomas, corporaciones locales, entidades religiosas y Administración del Estado. Es decir, para la creación y ampliación de plazas se otorgaba preferencia a las entidades públicas. El plan asimismo pretendía fomentar la vía del voluntariado; optimizar, mediante la mejora de la gestión, la completa utilización de los puestos de actividad disponibles; fomentar reuniones con las entidades colaboradoras más importantes; y elaborar un nuevo Reglamento para re gular la materia.

El plan presuponía explícitamente que el número de objetores se iba a estabilizar y que se podía aumentar el número de plazas. H ay que tener en cuenta que, al existir una gran bolsa de objetores pendientes de realizar su prestación, era preciso obtener plazas que no sólo cubrieran los nuevos reconocimientos de obje ción, sino que absorbieran los anteriormente existentes. A estos efectos, se ponían muchas esperanzas en la Ley del Voluntariado.

Como puede observarse, el plan, al igual que el de 1994, renunciaba a actuar sobre la variable del reconocimiento de los objetores, es decir, se renunciaba a conseguir una reducción de la oferta de objetores, salvo la que pudiera derivarse de la flexibilización en la apreciación de causas de exención y aplazamiento, así como de la aplicación de la Ley del Voluntariado. Se siguió optando, pues, por una política de oferta de plazas mediante la creación de las mismas.

\section{Los resultados de la implantación del plan de choque. El aumento del número de objetores}

En contra de la hipótesis de que el número de objetores se estabilizaría - muy poco realista, por otra parte- , más bien ocurrió lo contrario. En 1996, 1997, 1998 y 1999 se declararon objetores, respectivamente, 93.279, 127.303, 150.581 y 164.428 personas.

A ello contribuyeron una serie de causas. El mero anuncio de la profesionalización de las Fuerzas Armadas disparó el número de declaraciones de objeción en los primeros meses de 1996, y posteriormente, el aumento fue imparable. A ello hay que añadir la importancia de la difusión por los medios de comunicación de determinados hechos luctuosos en las Fuerzas Armadas, así como la existencia de conflictos bélicos en los que intervenían militares españoles44.

Pero en este periodo hay que tener en cuenta, sobre todo, un dato externo de una gran importancia: la disminución del paro juvenil. Las posibilidades de la juventud de encontrar un puesto de trabajo eran muy grandes, lo cual suponía un desincentivo para realizar el servicio militar, pues era muy difícil compatibilizar éste con la realización de una actividad laboral. Por el contrario, dado que el nivel de exigencia de la prestación social era muy inferior, ello contribuyó a hacer más grande el número de quienes se declaraban objetores45.

En este sentido, cabe observar que se contemplaba la prestación como una forma de seguir llevando el ritmo normal de vida, sin que su realización supusiera renuncia al trabajo 0 a los estudios, sobre la base de que las propias entidades darían prevalencia de los intereses de los objetores sobre los de la prestación. Pero esta idea inspiraba no sólo a los propios objetores y a muchas de las entidades, sino incluso al propio M inisterio de Justicia. Es muy significativo el convenio marco entre los M inisterios de Asuntos Exteriores, de Justicia y de Trabajo y de Asuntos Sociales, relativo a programas de prestación social de objetores de conciencia en el exterior, firmado el 23 de julio de 1997. Según la M inistra de Justicia, para evitar que los objetores residentes en el extranjero por motivos de trabajo o estudios tuvieran que venir a España para cumplir la prestación social, «desde esa fecha tienen la posibilidad de realizarla en los países de residencia, eliminándose así el quebranto que para su formación o perspectivas laborales representaba tener que desplazarse a España» (M J, 145). Como puede observarse, la idea implícita en esta declaración era la de que realmente la prestación social no iba a incidir apenas en su vida laboral o familiar.

Las consecuencias eran obvias: dado que declararse objetor y realizar la prestación no llevaba consigo ninguno de los inconvenientes del servicio militar, y sí muchas ventajas, muy pocos estaban dispuestos a hacer éste.

Por otro lado, en esta época se produjo un cambio de perspectiva de la sociedad, que ya se venía fraguando desde antes: en los primeros años de funcionamiento del sistema la sociedad veía al objetor como un sujeto cuando menos «extraño», si no sospechoso. En cambio, en esta época, en la que prácticamente sólo realizaba el servicio militar quien aśl lo deseaba, era a estas personas a las que se comenzaba a mirar con extrañeza y sospecha.

Por lo demás, el Consejo siguió con su política de gran amplitud a la hora de reconocer la condición de objetor. D e esta forma, hasta 1999 se habían presentado 903.309 solicitudes de reconocimiento de la condición de objetor; y se habían produci- 
do 857.678 reconocimientos. Es decir, el porcentaje de reconocimientos sobre las solicitudes era del $94,94 \%$.

\section{La creación de plazas}

En lo relativo a la creación de plazas el plan se cumplió con creces. La política de creación de plazas funcionó a pleno rendimiento. D e esta forma, los puestos existentes en 1996, 1997 y 1998 eran, respectivamente, 91.601, 108.517 y 126.143. Esas plazas se tendieron a buscar en aquellos lugares en que había bolsa de objetores pendientes, no en aquellos lugares en que predominaban las necesidades sociales.

Pero la gran creación de plazas tuvo el precio de la nula calidad de una gran parte de ellas (M J, 280)46. Esta falta de calidad, unida al escaso interés puesto por muchos de los objetores, daba lugar a una escasa rentabilidad social. Es muy significativo, por ejemplo, el informe del D efensor del Pueblo andaluz sobre Bibliotecas públicas municipales, fechado en diciembre de 2000 , según el cual «a colaboración de objetores, aunque puede proporcionar apoyo para cubrir determinados servicios, supone a la postre problemas para la calidad de la gestión bibliotecaria por la inestabilidad, poca motivación y escasa implicación de estas personas en el trabajo que desarrollan, que ha llevado, en no pocos caSOS, a que las personas responsables de las bibliotecas opten por no solicitar la colaboración de objetores) (SEVILLA, 2001, pág. 340).

Sólo en los últimos tiempos, a partir de 1999, empezaron a suprimirse plazas (MJ, 283). La página web del M inisterio de Justicia explicaba que ello era consecuencia del plan de mejora de la calidad, que permitía rescindir conciertos con entidades de escasa utilidad social. Pero el motivo real fue más bien, como luego veremos, el de la reducción del número de objetores, no el aumento del nivel de exigencia.

El plan ponía el acento en los conciertos con entes públicos, en especial Comunidades Autónomas y corporaciones locales. De hecho, cabe observar que el mayor aumento se produjo en plazas de este tipo de entidades y, más en concreto, en los Ayuntamientos (M J, 268). Indudablemente existía una correlación entre este dato y el hecho de que la objeción dejara de ser un fenómeno urbano y no rural. Pero también concurría otra causa aún más importante: las entidades públicas, y en particular, los Ayuntamientos, concebían la prestación social como un servicio más a prestar a los jóvenes - y a sus familias - ; y no al contrario. Q uiere ello decir que predominaba en estas entidades, por encima de los servicios que los objetores pudieran prestar a la sociedad, el interés por ofertar una prestación liviana a los obligados a ella, de modo que les permitiera continuar con su vidalaboral y familiar normal.
También se pretendía que la propia Administración del Estado colaborara, pero los resultados no fueron especialmente brillantes.

Por otra parte, la promoción de puestos con alojamiento y manutención con la simultánea intención de mantener la auste ridad presupuestaria constituía una contradicción palmaria. De hecho, el número de este tipo de plazas continuó reduciéndose, quedando prácticamente limitadas a los programas de cooperación internacional 47.

\section{Los efectos de la Ley del Voluntariado}

Por lo que se refiere a los mecanismos de la Ley del Voluntariado, es en este periodo cuando realmente se ponen en práctica las decisiones contenidas en dicha Ley, aunque no dieron el resultado apetecido. En efecto, las convalidaciones de servicios voluntarios fueron 758 (en 1996), 6.234 (en 1997), 10.770 (en 1998), y 13.168 (en 1999) (M J, 299). Como puede observarse, su desproporción con respecto al número de objetores reconocidos en cada año era manifiesta. Lo cual demuestra que, al menos para los objetores, el régimen de la prestación social era más atractivo que el del voluntariado, lo que es muy sintomático de la escasa exigencia de tal prestación, pues de lo contrario no se explica esta preferencia de un régimen basado en la forzosidad y coactividad sobre un régimen basado en la voluntariedad.

Porque, además, el control del sistema del voluntariado fue mínimo. Por un lado, las solicitudes desestimadas fueron muy escasas; y por otro lado, no se controló efectivamente la realidad de los servicios voluntarios certificados por las entidades, certificados que servían de base al reconocimiento de tales servicios de voluntariado.

\section{La mejora de la eficacia de la gestión administrativa}

En cuanto a la mejora de la eficacia de los procedimientos de gestión, los resultados fueron importantes:

En 1998 desapareció el «lamamiento», tal como se había entendido hasta entonces, y que provocaba tantos desfases temporales en la cobertura de plazas. A partir de ese año, cuando un objetor era reconocido por el Consejo, se le enviaba el modelo de manifestación de preferencia a fin de poder ser incorporado inmediatamente salvo falta de puesto de actividad48, consiguiendo así no interrumpir los servicios de los objetores a causa del lapso entre el licenciamiento de uno y la incorporación del siguiente a un mismo puesto.

Además, desde mediados de 1997 se puso en práctica el sistema del mutuo acuerdo, en virtud del cual una entidad se comprometía a admitir la incorporación de un objetor concreto $-y$ 
el M inisterio de Justicia a autorizarlo de manera inmediata- , con la particularidad de que ese objetor no ocupaba plaza concertada. Las ventajas del sistema eran varias: desde el punto de vista de la entidad, le permitía incorporar objetores en los que estaba interesada; desde el punto de vista del objetor, permitía su incorporación prácticamente inmediata; y desde el punto de vista del M inisterio de Justicia, permitía una reducción de la bolsa de objetores pendientes.

Sin embargo, la puesta en práctica del sistema del mutuo acuerdo y el hecho de que el reconocimiento de la condición de objetor obligaba a éste a el egir destino dio lugar al siguiente efecto, sobre todo en localidades donde sólo había una entidad (normalmente, el Ayuntamiento). Al verse obligado a elegir destino, el objetor se dirigía a esa entidad para que aceptara su incorporación por mutuo acuerdo. Ésta no solía negarse, a pesar de que no era capaz de dar ocupación efectiva a todos ellos, ya que anteponía el interés del objetor a la posible utilidad social que éste pudiera aportar. Lo cual ocasionaba que la realización de la prestación se concretara en un mero estar a disposición de la entidad. Es decir, el contenido de la prestación social era mínimo, lo que redundó en convertir a estos entes en una oficina de colocación pensando más en los objetores que en las actividades que podían realizar y, simultáneamente, un ejemplo, para los sucesivos aspirantes a objetor, al constatar la gran liviandad de la obligación sustitutoria del servicio militar.

Pero también hubo dificultades. En particular, un problema fundamental fue el de la asignación indiscriminada de objetores a los programas y entidades. D eterminados programas exigían de terminados perfiles de objetor, lo que era difícil de conseguir ante la masificación del sistema, y que se palió con la posibilidad de que las entidades designaran nominativamente a objetores concretos mediante el sistema de incorporación por mutuo acuerdo.

Asimismo, se produjo un importante aumento de la aplicación del régimen disciplinario en los casos de objetores conflictivos49, pero ello exigía una colaboración de las entidades que no siempre se producía.

\section{La evolución de la bolsa de objetores pendientes de realizar la prestación}

Entre 1996 y 1998 continuó existiendo una gran bolsa de objetores pendientes de incorporación, con las consiguientes tardanzas en su llamamiento50. Sin embargo, la adopción de las medidas arriba citadas y, en especial, la de la incorporación por mutuo acuerdo, dio lugar a que a mediados de 1998, aumentara extraordinariamente el número de quienes habían realizado o se encontraban realizando la prestación, produciéndose en muchos casos la incorporación del objetor en un plazo muy breve. El plan efectivamente permitió colocar a un gran número de obje- tores. Así, en abril de 1996 habían pasado 39.732 objetores a la reserva por cumplimiento de la prestación social; entre esa fecha y 30 de septiembre de 1998 lo hicieron 220.114 objetores. Ello no obsta para que si en unos lugares la incorporación se realizaba de forma muy rápida, en otros era mucho más lenta (MJ, 144), por la falta de adecuación en el plano geográfico entre la existencia de plazas y la existencia de objetores.

Por otra parte, todo hace pensar que se siguió una política de gran flexibilidad a la hora de reconocer exenciones y aplazamientos. Cabe observar que hasta 1999 se habían producido 857.678 reconocimientos de la condición de objetor de conciencia, habiendo realizado la prestación 482.527 objetores, lo que representaba el 56,25 \% de los reconocidos. El dato es revelador de que poco más de la mitad de los objetores reconocidos realizaron la prestación, lo que confirma la impresión social de que había más posibilidades de eximirse de las obligaciones por esta vía que por la del servicio militar.

\section{La promulgación de una nueva Ley de 0 bjeción de Conciencia y de la Prestación Social Sustitutoria (Ley 22/1998, de 6 de julio) y sus efectos}

El desarrollo de la política pública diseñada desde el M inisterio de Justicia se vio perturbado por la intervención de otros actores políticos. En concreto, el grupo CiU consiguió que las Cortes tramitaran una nueva Ley de 0 bjeción de Conciencia y de la Prestación Social Sustitutoria, que fue aprobada el 6 de julio de 199851.

Esta Ley, indudablemente impuesta como consecuencia del apoyo del grupo CiU al gobierno minoritario del PP, modificó sustancial mente en al gunos aspectos el régimen de la objeción y de la prestación social. En primer lugar, la declaración de objeción realizada hasta el día inmediatamente anterior a la fecha de incorporación al servicio militar suspendía automáticamente dicha incorporación.

Se modificaba, además, la composición del Consejo Nacional de 0 bjeción de Conciencia, incluyendo entre sus miembros a un representante sindical y otro de las entidades de Voluntariado.

La nueva Ley igualaba la duración de la prestación social con la del servicio militar (9 meses). Los promotores fundamentaban este cambio en que la diferente duración entre la prestación social y el servicio militar constituía una discriminación con respecto a quienes realizaban aquélla. Curiosamente el propio M inisterio de Justicia acogía el argumento (M J, 145), ignorando la propia realidad de los hechos de una prestación social en todos los sentidos incomparablemente más benigna que el servicio militar.

Asimismo, se establecía un plazo máximo de espera de tres años entre el reconocimiento de la condición de objetor y el ini- 
cio del periodo de actividad, de forma que si en ese plazo no se producía la incorporación a la prestación por causa no imputable al objetor, éste pasaría a la situación de reserva.

La Ley fue desarrollada por un nuevo Reglamento (Real Decreto 700/1999, de 30 de abril), con escasas modificaciones respecto del anterior, sal vo las impuestas por las novedades de la Ley.

¿Q ué consecuencias prácticas derivaron de tales modificaciones normativas?

La ampliación del periodo de declaración de objeción causaba evidentes problemas organizativos a las Fuerzas Armadas, ya que era prácticamente imposible conocer con una cierta antelación el número de militares de reemplazo que al final acabarían incorporándose a cada Unidad. Curiosamente, durante los meses anteriores a la aprobación de la Ley el M inisterio de D efensa había planteado la propuesta de adelantar la declaración de obje ción con suspensión de incorporación a la fecha anterior a aqueIla en que se realizaba el sorteo de destinos militares (noviembre del año anterior al de incorporación) 52 .

La modificación de la composición del Consejo $\mathrm{N}$ acional de 0 bjeción de Conciencia carecía de todo sentido. Primero, porque este órgano se había mostrado absolutamente prescindible e inoperante. Segundo, porque si de lo que se trataba era de evaluar la seriedad de una declaración de objeción, no parece que los nuevos miembros tuvieran mucho que decir. Por otra parte, si se incluía un representante de las entidades de Voluntariado, ¿por qué no incluir un representante de los entes públicos, que al fin y al cabo aportaban el mayor número de plazas para la realización de la prestación social e incluso del voluntariado? Además, de esta forma los representantes de la Administración del Estado perdían su mayoría, lo que constituía, por lo demás, la prueba más pal pable de la nula relevancia que concedía ya por estas fechas el M inisterio de Justicia a este órgano, pues en caso contrario hubiera sido difícil que admitiera esta situación.

La reducción de la prestación social a 9 meses produjo un doble efecto. Por un lado, sirvió para hacer menos atractivo todavía el servicio militar en beneficio de la prestación social, Io que indudablemente supuso un aumento de declaraciones de objeción.

Frente a ello, la reducción de 13 a 9 meses de la prestación significaba que, a lo largo de un año, por un mismo puesto podía rotar más de un objetor, es decir, permitía absorber un mayor número de objetores. Por de pronto, como consecuencia de la entrada en vigor de la Ley en julio de 1998, pasaron a la reserva todos los objetores que en aquel momento llevaban más de 9 meses de prestación.

Sin embargo, es dudoso que este aumento de puestos disponibles prevaleciera sobre la ampliación de objetores que implicaba y sirviera para descongestionar la bolsa de los mismos. H ay que tener en cuenta que por entonces el sistema del mutuo acuerdo, en virtud del cual las entidades podían aceptar la incorporación de objetores aun cuando ya estuvieran todas las plazas cubiertas, hacía que el número teórico de plazas concertadas apenas fuera significativo.

En cuanto al plazo de caducidad de tres años, permitió pasar a la reserva directamente a 48.332 objetores (M J, 146). Lo cual revela que, a pesar del aumento del número de puestos, continuaba existiendo una gran bolsa que al cabo de los años seguían sin ser llamados para su incorporación, así como las dificultades para colocar a determinados objetores.

\section{Otras incidencias externas}

En el desarrollo de la política pública hay que prestar nuevamente atención a la actividad legislativa y judicial en el campo jurídico penal.

La Ley O rgánica 7/1998, de 5 de octubre, volvió a suavizar las penas, igualando además las previstas en el Código Penal para los delitos contra el deber de cumplimiento de la prestación social y contra el deber de prestación del servicio militar.

Por lo que se refiere a la actividad judicial, hay que destacar dos aspectos con amplia relevancia periodística, en esta época en la que ya no se imponen penas privativas de libertad: por un lado, la doctrina del Tribunal Supremo absolviendo a personas que no habían realizado la prestación social con el argumento de que habían sido llamados a la prestación cuando ya había caducado el plazo para ello. Por otro lado, estaba la tendencia de los jueces encargados de juzgar estos delitos a demorar la celebración de los juicios, en la creencia de que, una vez decidido el fin del servicio militar y la prestación social sustitutoria, carecía de sentido juzgar estos asuntos, bien por apreciar la falta de un bien jurídico protegido, bien por entender que una futura Ley despenalizaría la materia con efectos retroactivos 53.

\section{La terminación dela política pública}

En los últimos tiempos de repente empezó a reducirse a pasos agigantados la bolsa de objetores pendientes de real izar la prestación social, en lo que incidieron varios factores.

En primer lugar, comenzó a manifestarse un nuevo e inquie tante fenómeno: los efectos de la disminución de la natalidad, 
que daba lugar a que el número de jóvenes que cumplían los 18 años fuese mucho más reducido que los de años anteriores.

Asimismo, hay que tener en cuenta otro dato: las normas re glamentarias permitían que los objetores manifestaran su preferencia por realizar la prestación hasta los 24 años. Lo cual significa que si en 1997 una persona contaba con 18019 años, podía manifestar su preferencia para hacerlo a los 24 años, es decir, a partir de 2002, lo que de hecho le eximía de todo tipo de obligación54. D e esta forma, gran parte de los nacidos a partir de 1 de enero de 1978 pudo eximirse legalmente de la prestación social. Por lo demás, se produjo un notable aumento de las solicitudes de aplazamiento, claramente motivadas por el deseo de alcanzar la fecha de suspensión del servicio militar y de la prestación55.

La Ley 17/1999, de 18 de mayo, suspendió la prestación del servicio militar obligatorio a partir del día 31 de diciembre de 2002, aunque autorizaba al Gobierno para que, en función del proceso de profesionalización de los Ejércitos, pudiera modificar las fechas determinadas para acortar el periodo transitorio.

Ya por entonces era evidente el escaso éxito de la profesionalización de las Fuerzas Armadas. A penas había can didatos para muchas de las plazas convocadas. Sin embargo, era imposible dar marcha atrás sin un elevado coste político.

En el año 2000 se celebraron nuevas elecciones generales. El PSOE en su programa electoral había propuesto la suspensión del servicio militar y de la prestación social a partir de 1 de enero de 2001. El Partido Popular reaccionó proponiendo el adelantamiento de la suspensión del servicio militar y la prestación social a partir del 1 de enero de 2002. Esta propuesta fue confirmada en el discurso de investidura del Presidente del Gobierno.

El Real D ecreto 247/2001, de 9 de marzo, adelantó a 31 de diciembre de 2001 la fecha de suspensión del servicio militar y, poco después, el Real Decreto 342/2001, de 4 de abril, suspendía a partir de esa misma fecha la prestación social sustitutoria del servicio militar.
Entre tanto, se planteó la cuestión de qué ocurriría, cuando se suspendiera la prestación social, con las tareas que venían realizando los objetores. Se estudió la implantación de un servicio civil para fines de interés general sobre la base del voluntariado, y desligado de toda idea de subsidiariedad con respecto a las obligaciones militares. Sin embargo, inmediatamente surgieron las críticas: los sindicatos y la oposición reprochaban que con ello se pretendía ocupar puestos de trabajo; las Comunidades Autónomas, por su parte, entendían que la gestión de ese servicio les correspondía a ellas, para lo cual reclamaban los recursos económicos antes destinados a la prestación social. Asimismo, el $M$ inisterio de Justicia consideraba que realmente sólo un 250 $30 \%$ de los puestos ocupados por objetores tenía una utilidad social, y que la mayor parte de los puestos se había creado con el único fin de hacer frente a la avalancha de objetores, por lo que su eliminación no causaría excesivos problemas56. En estas circunstancias, el M inisterio de Justicia, a la vista de que la implantación de un servicio civil podía crear más inconvenientes que ventajas, consideró prudente olvidar tales proyectos, es decir, adoptó la política de no hacer nada.

El colofón fue la Ley O rgánica 3/2002, de 22 de mayo, que dejó sin contenido los arts. 527 y 604 del Código Penal, es decir, los delitos de insumisión a la prestación social y al servicio militar obligatorio, y además con carácter retroactivo, ya que ordenaba revisar todas las sentencias condenatorias no ejecutadas totalmente, cancelar de oficio los antecedentes penales derivados de dichos delitos, incluso en el supuesto de sentencias totalmente ejecutadas; y sobreseer y archivar todos los procedimientos penales en los que no hubiera recaído sentencia firme57.

Se ponía así fin a esta política pública igualando a los que hicieron el servicio militar o la prestación social sustitutoria, y a los que no hicieron ni uno ni otra, con independencia de los motivos. Con ello evidentemente se evitaban numerosos problemas políticos, pero mostraba a las claras el valor que los poderes públicos daban a estas prestaciones forzosas y, en especial, a la prestación social sustitutoria58.

\footnotetext{
* Doctor en Derecho. Profesor Asociado de Derecho Administrativo de la Universidad de Sevilla.

1 M adrid, 2001. En lo sucesivo se mencionará con la abreviatura M J y la página concreta a la que se refiere la cita.

2 Las menciones se harán de acuerdo con las siguientes abreviaturas, seguidas por la fecha de la sesión: CJICD : Comisión de Justicia el nterior del Congreso de los Diputados; CD CD: Comisión de D efensa del Congreso de los Diputados; CDS: Comisión de D efensa del Senado; CJS: Comisión de Justicia del Senado.

3 Este error lo sufre el propio Congreso de los Diputados, cuando se solicitó la comparecencia del presidente del Consejo ante la Comisión de Justicia e Interior, en sesión de 19/6/1991, para plantearle cuestiones que fundamental mente afectaban a la oficina.
}

4 Las fuentes no dejan lugar a dudas. Así lo confirman los repertorios de jurisprudencia y las declaraciones ante las $C$ omisiones de las Cortes. Vid., por ejemplo, CJICD 19/06/1991, 22/06/1992, 3/03/1993 y 23/02/1994.

5 Vid., por ejemplo, CJICD 19/06/1991.

6 Todas las fuentes son coincidentes en este punto, Vid., por ejemplo, $A B C$ 8/01/1994, editorial de El País 16/03/1994; Vid. asimismo las manifestaciones en CJICD 19/06/1991, CDCD 1/12/1992, CDCD 7/04/1994, CJS 6/04/1994, CDCD 4/10/1994. Vid. M J, 226, sobre la renuncia a la condición de objetor con análogos fines.

7 Esta diferente duración entre el servicio militar y la prestación social fue también otro factor de deslegitimación de esta última, con el argumento de su carácter discriminatorio. 
8 Bastaba con poner las palabras exactas que decía la Ley para que el Consejo reconociera la condición de objetor, de forma que este reconocimiento podía considerarse automático (vid., por ejemplo, CDCD 22/10/1991). Según el presidente del Consejo (CIICD 19/06/1991), en la fecha de su comparecencia sólo se habían interpuesto 419 recursos contencioso administrativos, lo que demuestra que el Consejo aceptaba la mayor parte de las declaraciones. Este mismo presidente indicaba los motivos por los que se había denegado el reconocimiento, lo que demuestra que a los objetores de conveniencia el Consejo no les planteaba ningún problema. Vid. una crítica soterrada a este resultado y a la independencia del Consejo, en CJICD 22/06/1992, por parte del Director General Asuntos Religiosos y de 0 bjeción de Conciencia.

9 Vid. CJS 6/04/1994, que recoge manifestaciones del M inistro de Justicia. Vid. también CD CD 23/03/1993, El País 11/3/1994, El M undo 12/11/2000; así como el Informe anual 1993 del D efensor del Pueblo.

10 Vid. las Leyes de Servicios Sociales de Cataluña (26/1985); C astilla-La M ancha (3/1986); C astilla y León (5/1987); A ragón (4/1987); Canarias (9/1987); Extremadura (5/1987); Galicia (4/1993); Ley del Voluntariado 9/1992 (Aragón).

11 Vid. bolsa n- 9 de puestos de actividad, correspondiente a noviembre de 1993.

12 Vid. los datos expuestos en C IICD 19/6/1991.

13 CJICD 20/12/1993.

14 Es significativa la primera comparecencia del M inistro DE LA QUADRA-SALCEDO para exponer su política ante la Comisión de Justicia e Interior del Congreso (sesión de 16/04/1991): en su exposición no hace ninguna mención a los problemas de la objeción de conciencia y de la prestación social; sólo cuando determinados grupos minoritarios aluden al tema, se ve obligado a decir al go sobreél.

15 CJS 6/04/1994.

16 Vid., por ejemplo, CDCD 1/12/1992.

17 Vid. sobre este punto, por ejemplo, CJICD 29/04/1992.

18 El País27/02/1994.Vid. M J, 169-171.

19 Vid., por ejemplo, Informes anuales del D efensor del Pueblo de 1991 (pág. 147) y 1992 (pág. 150).

20 Por ejemplo, sólo había dos médicos para resolver todas las solicitudes de exención y aplazamiento por causas médicas (Vid. CJICD 23/02/1994).

21 El País 7/04/1994 (F. L. de Sepúlveda) y 6/11/1994, CDCD 1/12/1992; CDCD 7/04/1994.

22 El Pá́s 11/03/1994 y 12/03/1994.

23 El M undo 16/03/1994.

$24 \mathrm{Vid}$. las manifestaciones en este sentido del Director $G$ eneral Asuntos Religiosos y de 0 bjeción de Conciencia ante la Comisión de Justicia e Interior del Congreso (C)ICD 23/02/1994).

25 Las encuestas del CIS reflejaban una amplia creencia social según la cual predominaba la objeción de conveniencia sobre la de conciencia (El País 10/08/1994).

26 El País20/04/1994.

27 El M undo 22/11/1995, El Diario de Cádiz 10/11/1996.

28 Vid., por ejemplo, ABC 29/07/1996; M J, 127, 179; Informe anual de 1994 del D efensor del Pueblo, pág. 165.

29 Todas las fuentes son coincidentes. Vid., por ejemplo, CD CD 22/10/1991. Es significativo que el porcentaje de objetores entre los que eran destinados a Ceuta y $\mathrm{Me}$ lilla era muy superior a la media.

30 CJICD 20/12/1993.

31 Las entidades colaboradoras muchas veces no sabían qué hacer con los objetores que les eran asignados, porque no había proyecto ni programa previo para que desarrollasen su actividad, poniéndose el acento, en la creación de plazas, más en la cantidad que en la calidad (Vid. CJS 6/04/1994).

32 Vid., por ejemplo, El M undo 22/11/1995.
33 Vid., por ejemplo, el Decreto 22/95 de 9 de marzo, de la Comunidad de M adrid, que crea la 0 ficina Regional de 0 bjeción de Conciencia y Servicio M ilitar dependiente de la D irección General de Juventud.

$34 \mathrm{El}$ M undo 22/11/1995, M J, 132

35 Es significativa la contestación a una pregunta parlamentaria por el Secretario de Estado de Administración M ilitar: la Cruz Roja prefería soldados de reemplazo a cualquier otro colectivo, en clara referencia a los objetores (DSS 24/04/1995).

36 Vid., por ejemplo, El M undo 13/02/1998.

37 Vid., por ejemplo, El País8/07/1994 y editorial de ABC 9/07/1994.

38 A partir de 11 de julio de 1994, los módulos mensuales fueron de 35.200 pesetas por alojamiento y manutención y 8.200 sólo por la manutención (MI, 182). El cuz dro de M I, 182 muestra, a la vista de los créditos presupuestarios existentes para este fin, que, en el mejor de los casos, el número de plazas con alojamiento y manutención no llegó a pasar de las 1.000, aunque sin duda fueron muy inferiores.

39 El diario ABC 19/03/1994 contiene una noticia que se comenta por sí sola: el IN SERSO ofrecía 3.200 plazas para realizar la prestación. Sin embargo, en un periodo de 6 años sólo 35 objetores habían realizado su prestación en esa entidad.

40 Para constatarlo basta con un simple detalle. En el libro editado por el M inisterio de Justicia, que reiteradamente venimos citando, la exposición del plan ocupa 15 pá ginas (219-233); por contra, los resultados se despachan en poco más de una página (236-237). La situación se califica de «casi colapso» (M), 126, 133).

41 Vid., por ejemplo, El País 19/08/1994 y 15/11/1994.

42 Vid., por ejemplo, El País20/10/1994.

43 El País 18/03/1994, El M undo 22/11/1995.

44 Vid., por ejemplo, El País 15/9/1997 y 5/5/1999.

45 Vid. declaraciones del Director General de 0 bjeción de Conciencia en EI M undo, 28/10/1996. Sobre la percepción de los propios objetores, Vid. Diario de Cádiz 10/11/1996, El País 15/12/1999 y ABC 15/10/2000.

46 Así lo reconocía el propio Director General de O bjeción de Conciencia (El País $12 / 01 / 2000)$.

47 Vid., por ejemplo, la relación de puestos de actividad publicada en el BOE de 5 de febrero de 1999.

48 Página web del M inisterio de Justicia www .mju.es/objecion.

49 ABC 30/07/1996; M J,284.

50 Vid., por ejemplo, El M undo 19/07/1996: según el Ministerio de D efensa sólo el 19\% de los objetores había realizado la prestación, existiendo cerca de 200.000 pendientes de hacerla; un objetor tardaba entre dos y cuatro años en incorporarse. Según $A B C$ 29/07/1996, en abril de 1996 había 47.678 objetores en activo. A 31/12/1997 el núme ro de objetores pendientes de cumplir la prestación era de 115.985 (ABC 31/03/1998).

51 La proposición de Ley se publicó en el Boletín Oficial de las Cortes $G$ enerales el 10/06/1996, quedando su tramitación paralizada durante mucho tiempo, hasta que al fin se decidió continuar con ella.

52 El País 24/10/1997. Vid. datos en El País 18/11/1996.

53 Vid., por ejemplo, El País16/6/1996, 24/2/97, 30/7/97 y editorial de 28/2/98.

54 C omo más arriba se ha indicado, en el servicio militar sólo se podía hacer hasta los 22 años, lo que constituía otro aliciente para huir del régimen del servicio militar en dirección al de la objeción.

55 Vid. La Razón 17/10/1999. Vid. El País 15/05/1998 y editorial de El País $11 / 11 / 1999$.

56 El País 12/1/2000.

57 H asta 1999 se habían tramitado casi 10.000 denuncias ante el M inisterio Fiscal (M), 284).

58 Valor muy lejano al triunfalismo que se desprende de la presentación del libro M J, 13-14. 